\title{
Gien, un château royal entre rupture et continuité avec l'œuvre de Louis XI
}

Mélinda Bizri, Sylvie Marchant et Christophe Perrault

\section{OpenEdition}

1 Journals

Édition électronique

URL : https://journals.openedition.org/cem/16408

DOI : $10.4000 /$ cem. 16408

ISSN : 1954-3093

\section{Éditeur}

Centre d'études médiévales Saint-Germain d'Auxerre

\section{Référence électronique}

Mélinda Bizri, Sylvie Marchant et Christophe Perrault, « Gien, un château royal entre rupture et continuité avec l'œuvre de Louis XI », Bulletin du centre d'études médiévales d'Auxerre / BUCEMA [En ligne], 23.1 | 2019, mis en ligne le 01 septembre 2019, consulté le 22 septembre 2022. URL : http:// journals.openedition.org/cem/16408; DOI : https://doi.org/10.4000/cem.16408

Ce document a été généré automatiquement le 22 septembre 2022.

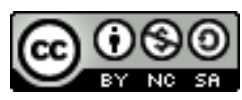

Creative Commons - Attribution - Pas d'Utilisation Commerciale - Partage dans les Mêmes Conditions 4.0 International - CC BY-NC-SA 4.0

https://creativecommons.org/licenses/by-nc-sa/4.0/ 


\title{
Gien, un château royal entre rupture et continuité avec l'œuvre de Louis XI
}

\author{
Mélinda Bizri, Sylvie Marchant et Christophe Perrault
}

1 Le Val de Loire est connu pour les châteaux qui en parsèment le cours, notamment en aval d'Orléans. La résidence royale de Gien occupe une place atypique par rapport à cet ensemble. D'une part, il se situe bien en amont d'Orléans et, d'autre part, son élévation est marquée par l'usage de la brique, un matériau peu employé dans ces constructions (fig. 1 et 2 ).

Comme souvent pour les lieux situés en marge des grands sites touristiques, mais également universitaires, peu d'études récentes renouvellent véritablement l'histoire du Giennois. Si les nombreux articles du Bulletin de la Société historique, archéologique et artistique du Giennois, parus à partir de $1942^{1}$, retracent l'histoire des seigneurs du lieu ${ }^{2}$ ou mettent en lumière quelques épisodes historiques ${ }^{3}$, l'histoire

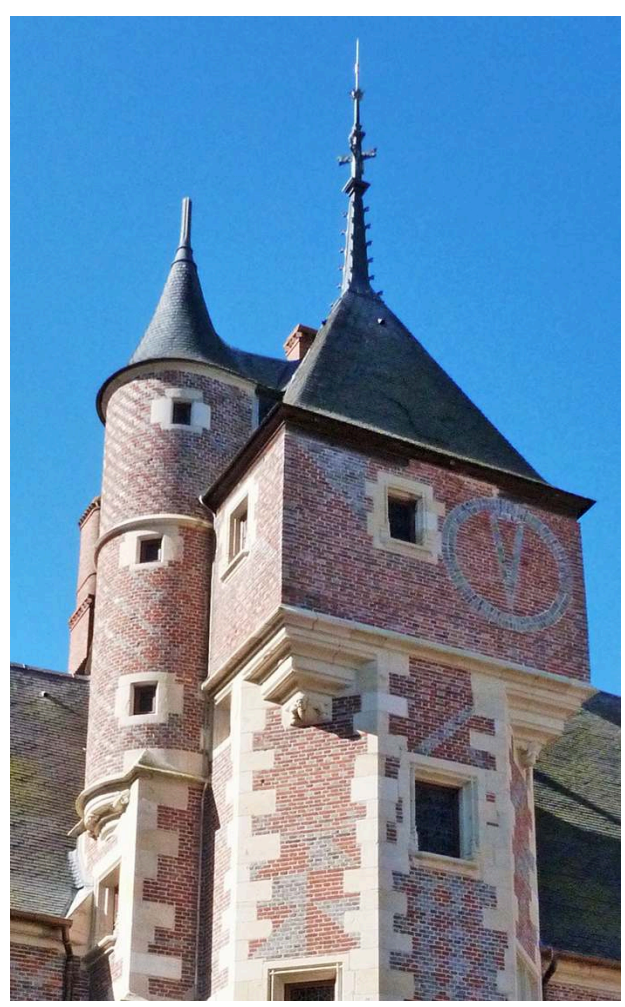
médiévale de la ville et la place qu'y occupe la résidence seigneuriale demeurent lacunaires ou peu publiées ${ }^{4}$.

3 Avec la réalisation d'un mémoire de maîtrise en 1994, un premier bilan documentaire concernant le château est dressé. Sylvie Salcedo-Marchant met alors en évidence et de 
manière inédite son histoire et la chronologie du chantier de construction ${ }^{5}$, alors qu'aucune archive (compte ou plan projet) n'a pu être retrouvée pour les périodes médiévale et moderne.

4 En 2012, un colloque tenu à Moulins sur la personnalité d'Anne de France permet la publication par Jean Guillaume d'une première synthèse sur le caractère particulier de l'architecture du château de Gien 6 . Il y propose une nouvelle chronologie d'édification, tenant compte de datations dendrochonologiques effectuées en 19987. Au même moment, le château de Gien fait l'objet d'une grande opération de conservationrestauration (2011-2015) impulsée par le Département du Loiret pour le musée de la Chasse, qu'il accueille depuis 1952. Aux études préalables et études de diagnostic des architectes en chef des Monuments historiques ${ }^{8}$, font suite des études documentaires ${ }^{9}$ et archéologiques ${ }^{10}$ et, enfin, une nouvelle campagne d'étude dendrochronologique ${ }^{11}$.

Fig. 1 - Gien, château, vue générale depuis le sud, façade Loire

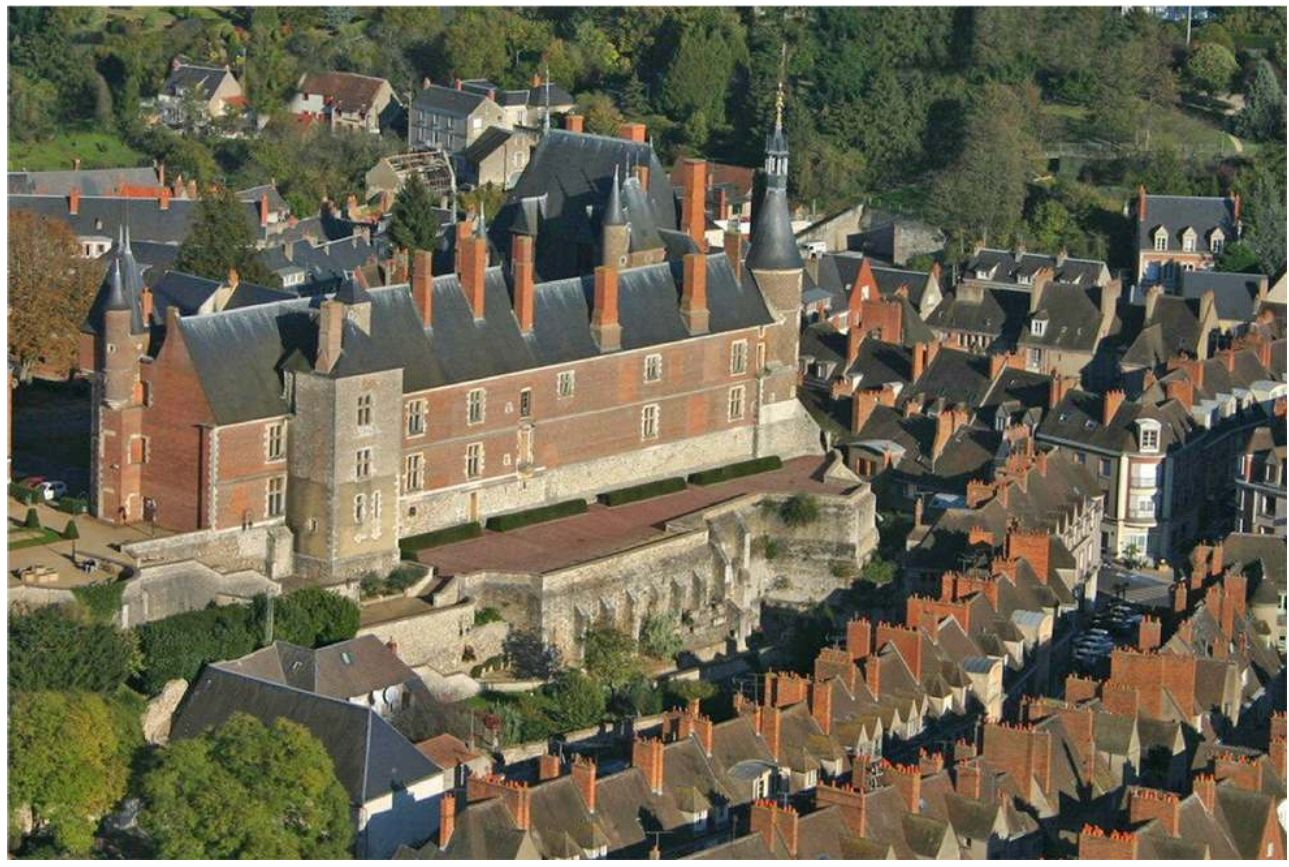

Cl. dép. du Loiret 
Fig. 2 - Gien, château, vue des façades en cour nord

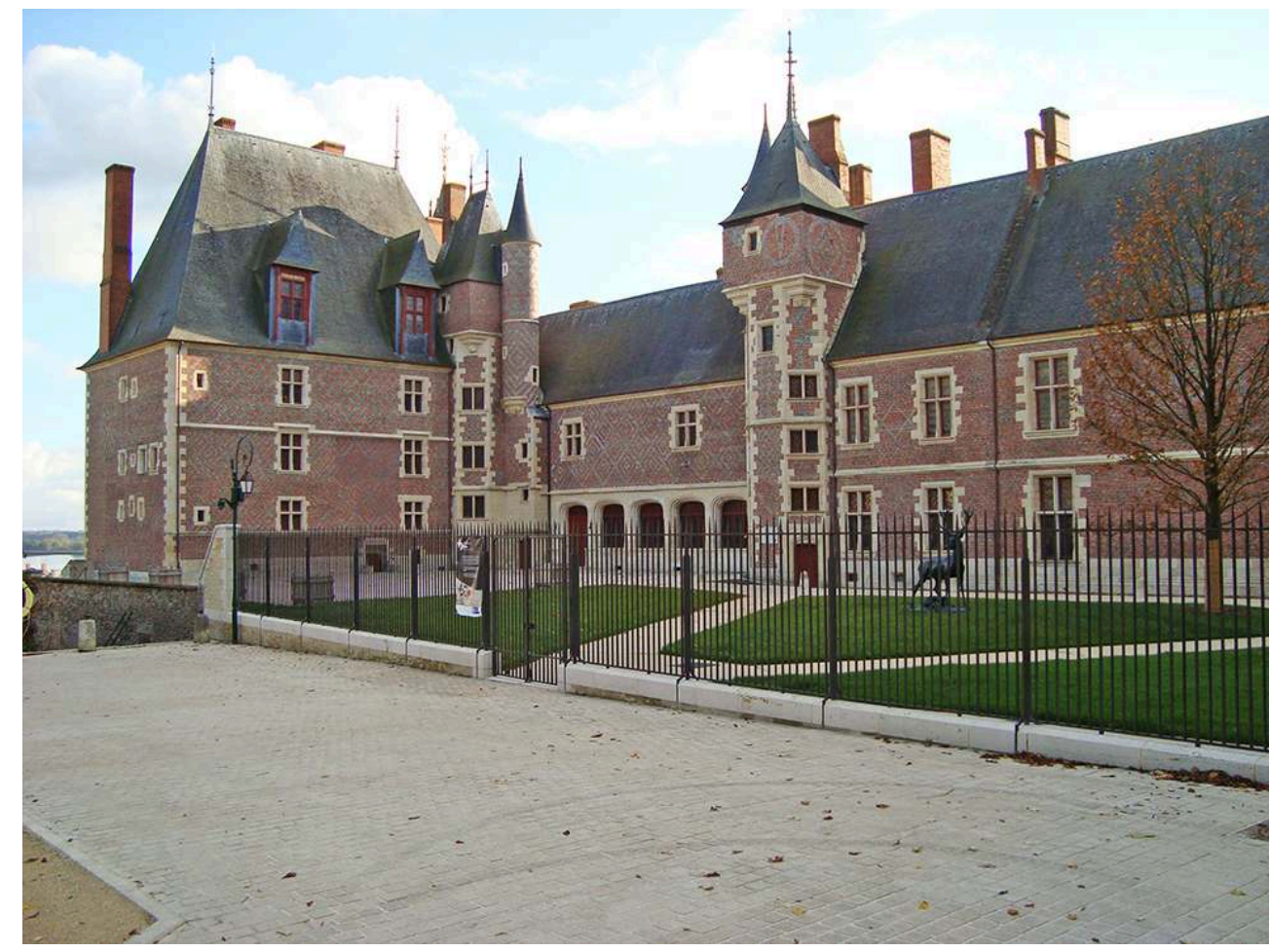

Cl. dép. du Loiret

\section{Un site à valeur stratégique pour la régence du royaume de 1483 à 1488}

5 Le château de Gien est construit en limite du diocèse d'Auxerre, dont il occupe l'extrémité nord-ouest. Le castrum précédant la construction de l'édifice de la fin du Moyen Âge relève de seigneurs bourguignons, les Donzy. Il rejoint le domaine royal à la charnière des $\mathrm{XII}^{\mathrm{e}}$ et $\mathrm{XIII}^{\mathrm{e}}$ siècles ${ }^{12}$. Après un temps de gestion du domaine en apanage et de nombreuses tensions à son propos, avec la branche des Valois et les ducs de Bourgogne, dont quelques éléments sont relatés ci-après, la seigneurie de Gien constitue la dot d'Anne de France, fille aînée de Louis XI, en $1481^{13}$. Elle assure la régence sous la minorité de Charles VIII, de 1483 à 1488.

6 Le contexte historico-politique précédant la période d'édification du château permet d'émettre plusieurs hypothèses sur les raisons de la construction d'une telle résidence royale à Gien.

7 Gien se place en limite du duché d'Orléans, des territoires bourguignons et des terres bourbonnaises, trois espaces tenus par des personnages politiques apparentés et aux relations marquées par des rivalités, avant et durant la régence d'Anne de France (fig. 3 et 4). 
Fig. 3 - Gien, la France historique sous Louis XI

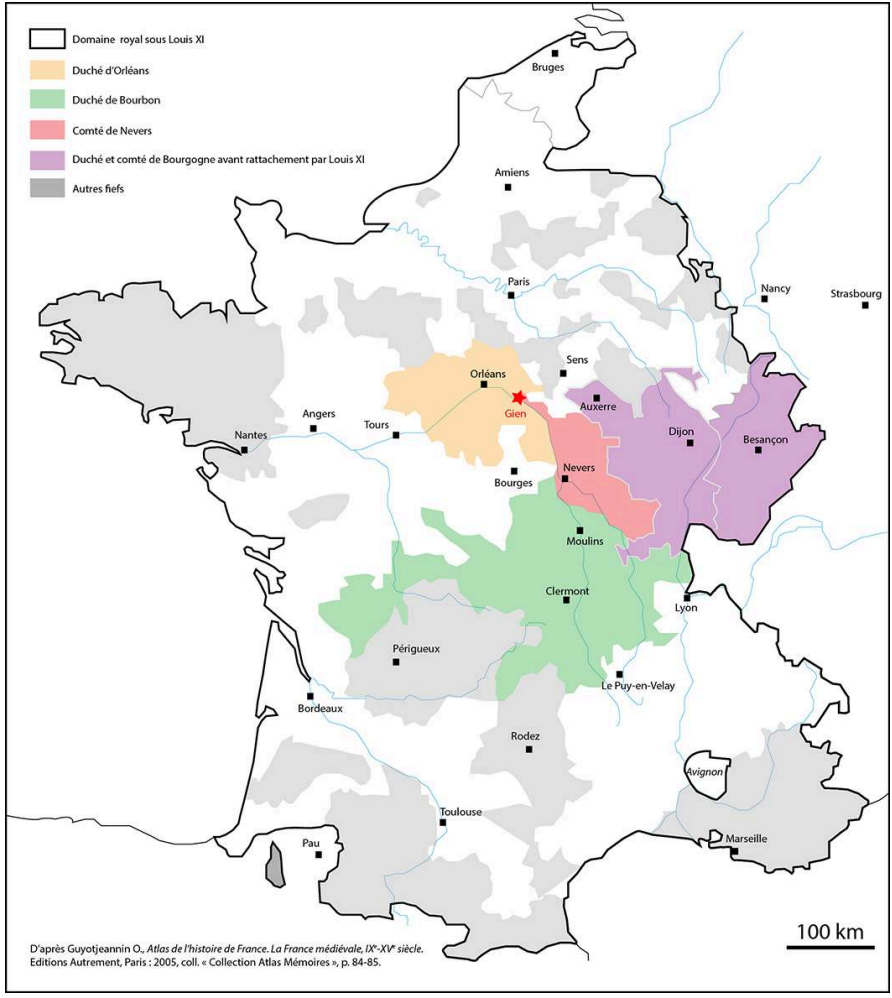

DAO M. Bizri

Fig. 4 - Gien, localisation des principaux lieux cités dans l'article

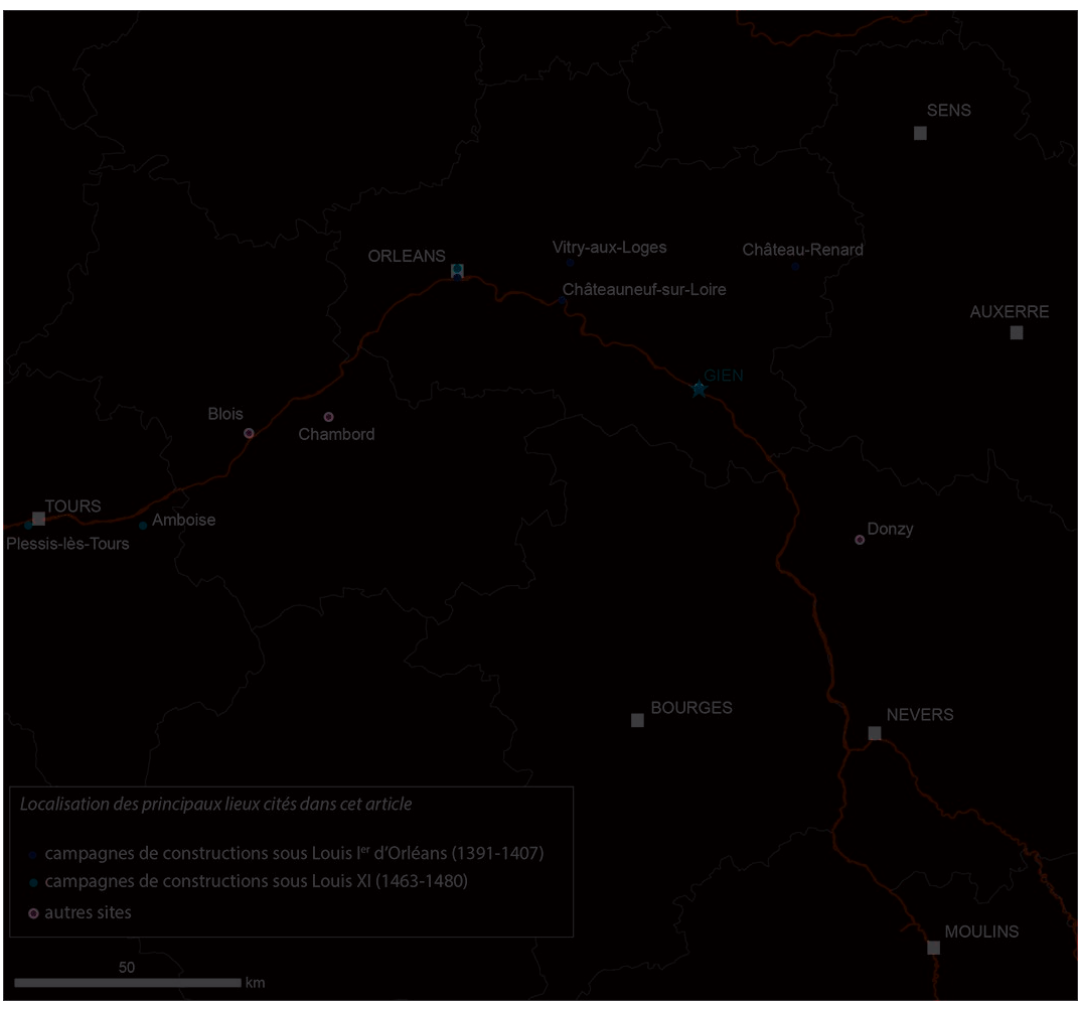

DAO M. Bizri 
Valois, est un personnage puissant, fervent opposant du duc de Bourgogne Philippe le Hardi. Il est assassiné par le duc de Bourgogne en 1407. Ce personnage est à l'origine de plusieurs édifices réalisés entre 1391 et 1407, Pierrefonds ou la Ferté-Milon pour les plus connus, au nord de Paris, et, dans le Loiret, à Orléans, au Châtelet, résidence ducale de la ville, à Châteaurenard, Vitry-aux-Loges ou encore Châteauneuf-sur-Loire, dont il ne reste que peu ou pas d'élévations ${ }^{14}$.

9 La seigneurie de Gien se situe au plus septentrional de l'apanage du duc de Berry. C'est sans doute pour cette raison que se tient à Gien, en 1410, un conseil réuni par le duc Jean de Berry, qui ligue des grands du royaume alors présents contre le duc de Bourgogne ${ }^{15}$ et scelle un accord par le contrat de mariage entre Charles d'Orléans (fils de Louis $\mathrm{I}^{\mathrm{er}}$ ) et Bonne d'Armagnac - fille du connétable Bernard VII d'Armagnac et de Bonne de Berry ${ }^{16}$. Cette alliance ouvre sur la querelle entre Armagnacs et Bourguignons dans le premier tiers $d u \mathrm{Xv}^{\mathrm{e}}$ siècle, période également marquée par les vicissitudes de la guerre de Cent Ans.

10 Lorsqu'Anne de France (1461-1522) accède à la régence du royaume, son autorité est remise en question par le duc d'Orléans (vers 1484), dans la continuité de ces luttes pour le trône de France ${ }^{17}$. Elle est la fille aînée de Louis XI et l'épouse de Pierre de Bourbon à partir de 1473. Pierre de Bourbon, cadet de la maison ducale de Bourbon, est devenu l'homme de confiance du roi Louis XI depuis $1472^{18}:$ il est régulièrement appelé au Conseil du roi, puis, en 1482, il s'occupe des affaires courantes du royaume, alors que la santé du roi Louis XI se dégrade ${ }^{19}$.

11 Louis II de Bourbon (1337-1410) avait impulsé en Bourbonnais de nouvelles constructions, notamment à Moulins, Bourbon-l'Archambault ou Billy ${ }^{20}$, alors que, dans le même temps, de vastes chantiers ont cours en Bourgogne - Palais des ducs à Dijon et en Berry - Mehun-sur-Yèvre, apanage du duc Jean de Berry (1360-1416). Depuis le duc Jean $I^{\text {er }}$ (1410-1434) et avant la trahison du connétable en 1523, le positionnement des ducs de Bourbon vis-à-vis de la royauté fluctue : tantôt ils soutiennent Charles d'Orléans dans la querelle entre Armagnacs et Bourguignons, tantôt ils ménagent leurs relations aux voisins bourguignons lors de leur ralliement, entres autres, aux ducs de Bourgogne (Charles le Téméraire) au moment de la Ligue du Bien public opposée à la politique royale de Louis XI, vers 1465 . Durant cette période, peu d'éléments renseignent sur Gien. Le territoire est confisqué par le futur Charles VII à la mort de Jean de Berry, afin que le domaine ne tombe pas aux mains du duc de Bourgogne, Philippe-le-Hardi, le propre frère de Jean.

$12 \mathrm{Au}$ cœur de ces territoires aux luttes politisées, Gien constitue un lieu chargé de sens pour la légitimation du pouvoir royal exercé par Anne de France et Pierre de Bourbon. Les choix opérés dans son édification traduisent ce contexte.

\section{Chronologie de la résidence royale}

Bâti sur un promontoire calcaire, le château se dresse sur la rive droite de la Loire. Il se compose aujourd'hui de deux ailes en retour d'équerre, distribuées par trois tourelles d'escalier surmontées de chambres hautes, rythmant les façades sur cour (fig. 5).

Bulletin du centre d'études médiévales d'Auxerre | BUCEMA, 23.1 | 2019 
Fig. 5 - Gien, plan complet du château et nomenclature des espaces

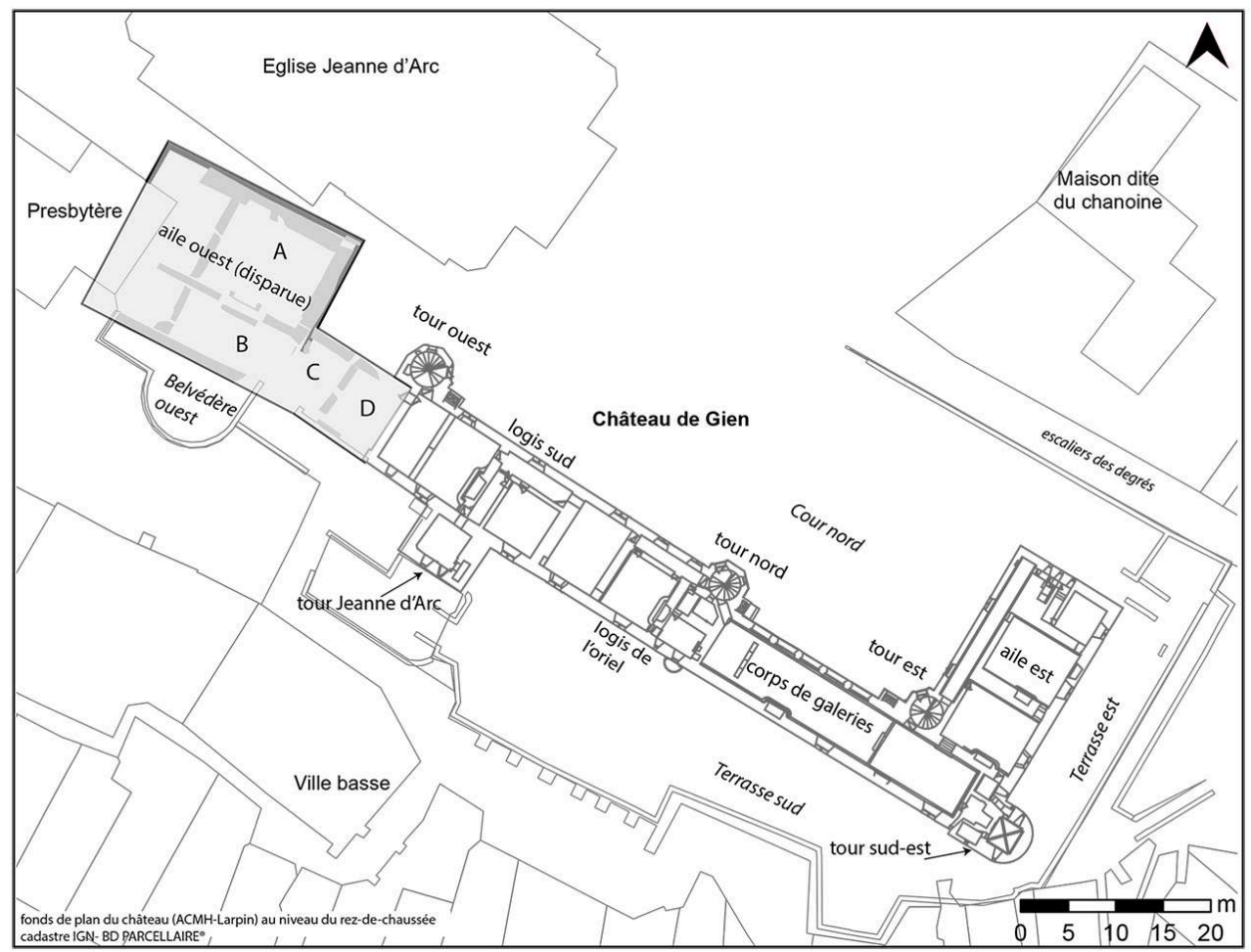

DAO M. Bizri

Cinquante-quatre échantillons prélevés sur les bois du château font apparaître quinze coupes de chênes sur une période de onze ans ${ }^{21}$, de l'automne-hiver 1481-1482 à l'automne-hiver 1492-1493 (fig. 6).

Fig. 6 - Gien, évolution spatio-temporelle du chantier

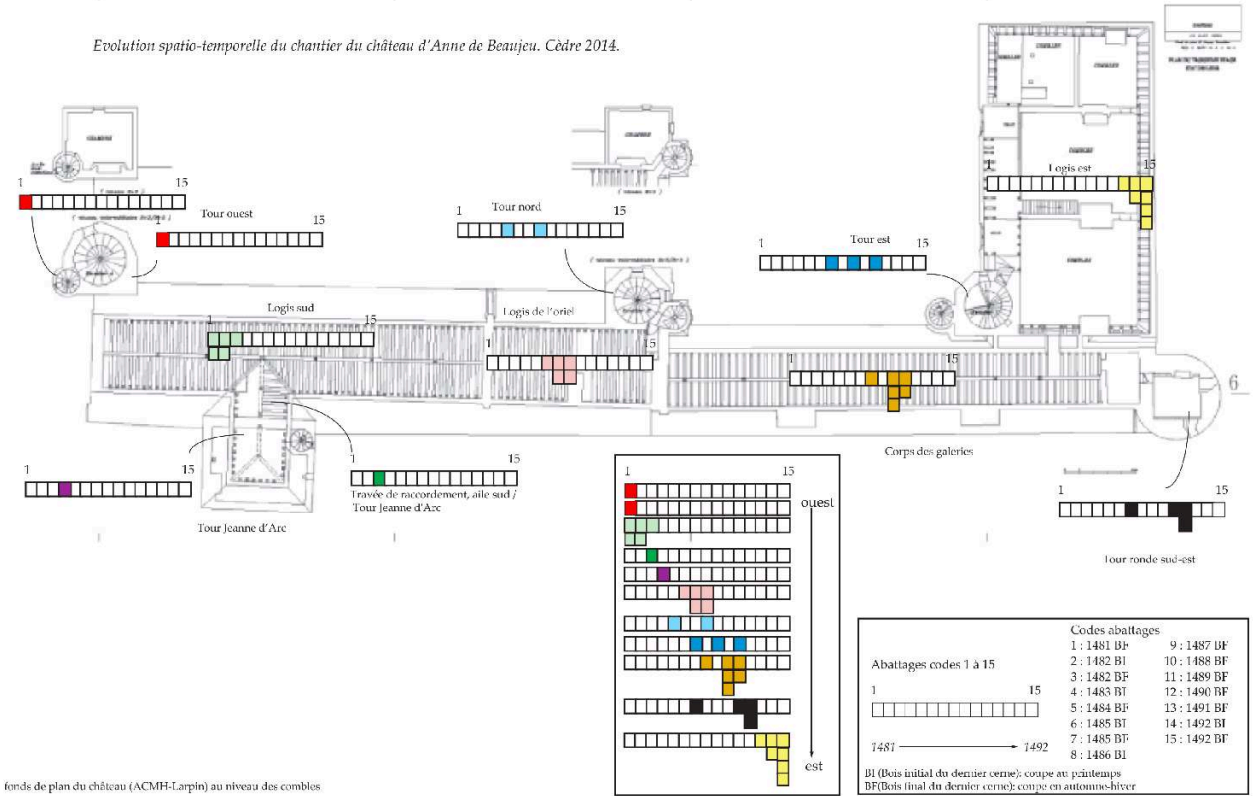

DAO C. Perrault 


\section{régulière du chantier d'ouest en est (fig. 7).}

Fig. 7 - Gien, progression du chantier entre 1481 et 1493

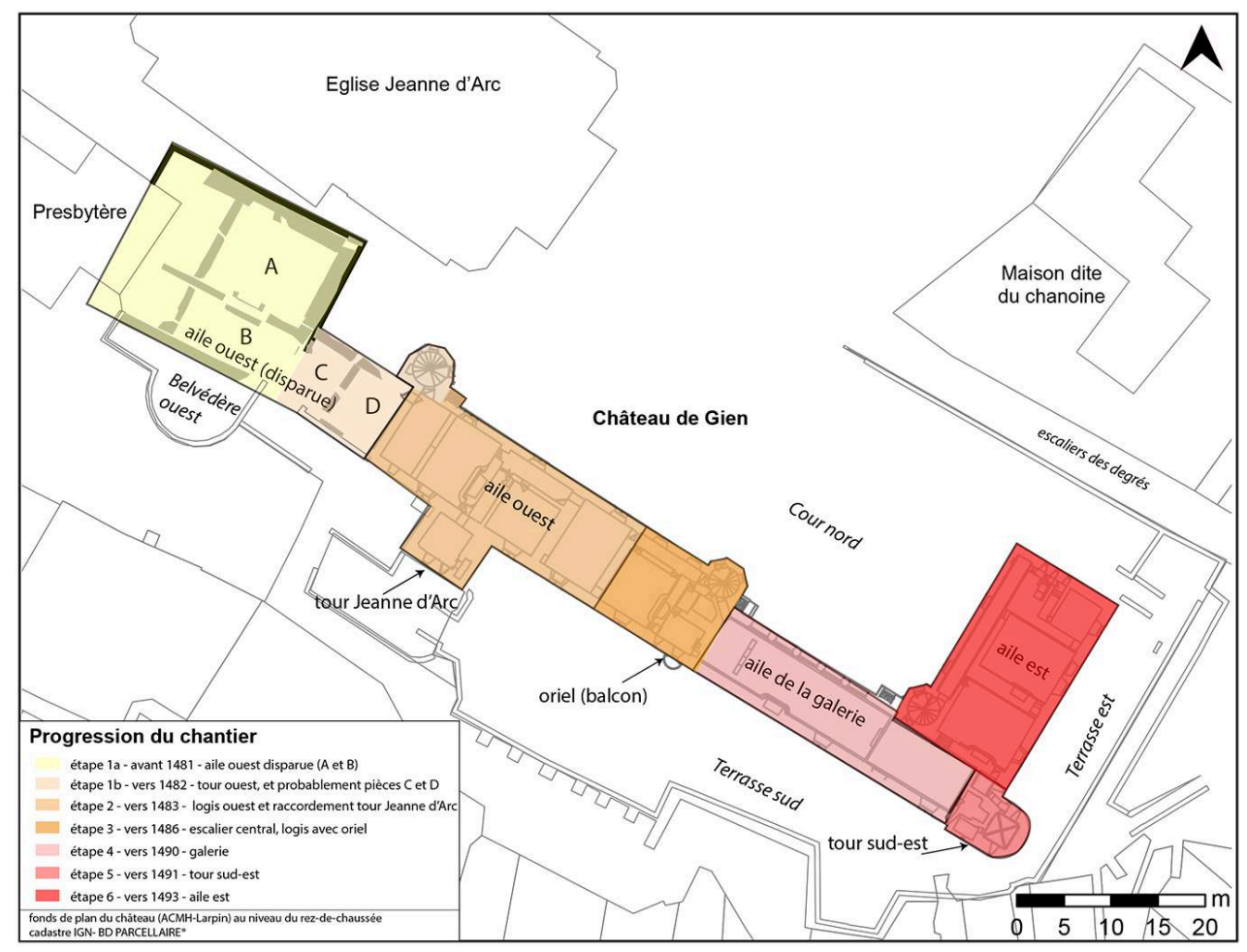

DAO M. Bizri

Les coupes de bois les plus anciennes sont localisées à l'ouest, dans la tour et la tourelle d'escalier ouest, distribuant une chambre haute sur l'escalier, alors que les plus récentes sont exclusivement associées à l'aile orientale. Si l'étude dendrochronologique permet de restituer au moins six étapes principales dans la construction, essentiellement basée sur les datations des charpentes ${ }^{22}$, la lecture du bâti et les découvertes archéologiques permettent d'ajouter une première phase de construction concernant l'aile ouest disparue. Ces phases sont les suivantes (cf. fig. 7) :

- $\mathrm{n}^{\circ} 1 \mathrm{a}$, avant 1481 , pour les pièces $A$ et $\mathrm{B}$ de l'aile ouest disparue ;

- $n^{\circ} 1 \mathrm{~b}$, vers 1482 , pour la charpente de la tourelle d'escalier et de la chambre haute de la tour ouest et pièces $C$ et $D$ de l'aile ouest disparue ;

$\cdot \mathrm{n}^{\circ} 2$, vers 1483 , pour le logis sud la tour Jeanne d'Arc située en façade sur Loire, et sa noue de raccordement au logis ;

- $n^{\circ} 3$, vers 1486 , pour le logis sud comportant un oriel et la tour d'escalier centrale ;

- $\mathrm{n}^{\circ} 4$, vers 1490 , pour le corps des galeries, avec éventuellement deux sous-étapes, vers 1489, à l'ouest, et, vers 1490, plus à l'est, corroborées par les deux séries distinctes de marques des assemblages ;

$\cdot \mathrm{n}^{\circ} 5$, vers 1491 , pour la tour ronde, au sud-est ;

$\cdot \mathrm{n}^{\circ} 6$, vers 1493 , pour l'aile est.

La construction d'une seule charpente nécessite plusieurs coupes de bois successives, sur deux à cinq années. Le chantier est donc alimenté progressivement et en continu en prévision des futurs travaux. L'hypothèse de la constitution d'un stock de bois alimenté 
régulièrement est confortée par la datation des bois et leur localisation dans le château. En effet, il a été constaté que la datation de pièces de bois issues des planchers et des charpentes est parfois inversée, avec des abattages plus récents dans les niveaux de planchers que dans les charpentes ${ }^{23}$. Ce constat renforce l'hypothèse d'une mise en œuvre des pièces seulement après obtention du volume de bois requis pour un ensemble donné - par logis et/ou par tour. Les restes de stock, eux, sont employés ailleurs dans la construction.

Cette logique de progression de chantier et de l'usage du matériau bois permet de proposer une étape de chantier hypothétique, qui commencerait par la réalisation des pièces A et B de l'aile ouest disparue (étape 1a), avant l'automne-hiver 1481, dans une phase initiale documentée par l'archéologie seulement, puis, l'édification des pièces $C$ et $\mathrm{D}$ de l'aile ouest, disparue (étape $1 \mathrm{~b}$ ) vers 1482, de manière concomitante avec la tour ouest.

\section{Étape 1a : les pièces A et B de l'aile disparue (avant l'automne-hiver 1481)}

Supposée par Sylvie Salcedo-Marchant et Jean Guillaume ${ }^{24}$, une aile arasée a été dégagée lors des fouilles menées en 2013 sur le belvédère ouest ${ }^{25}$ (fig. 8).

Fig. 8 - Gien, vue zénithale de l'aile ouest mise au jour lors des fouilles

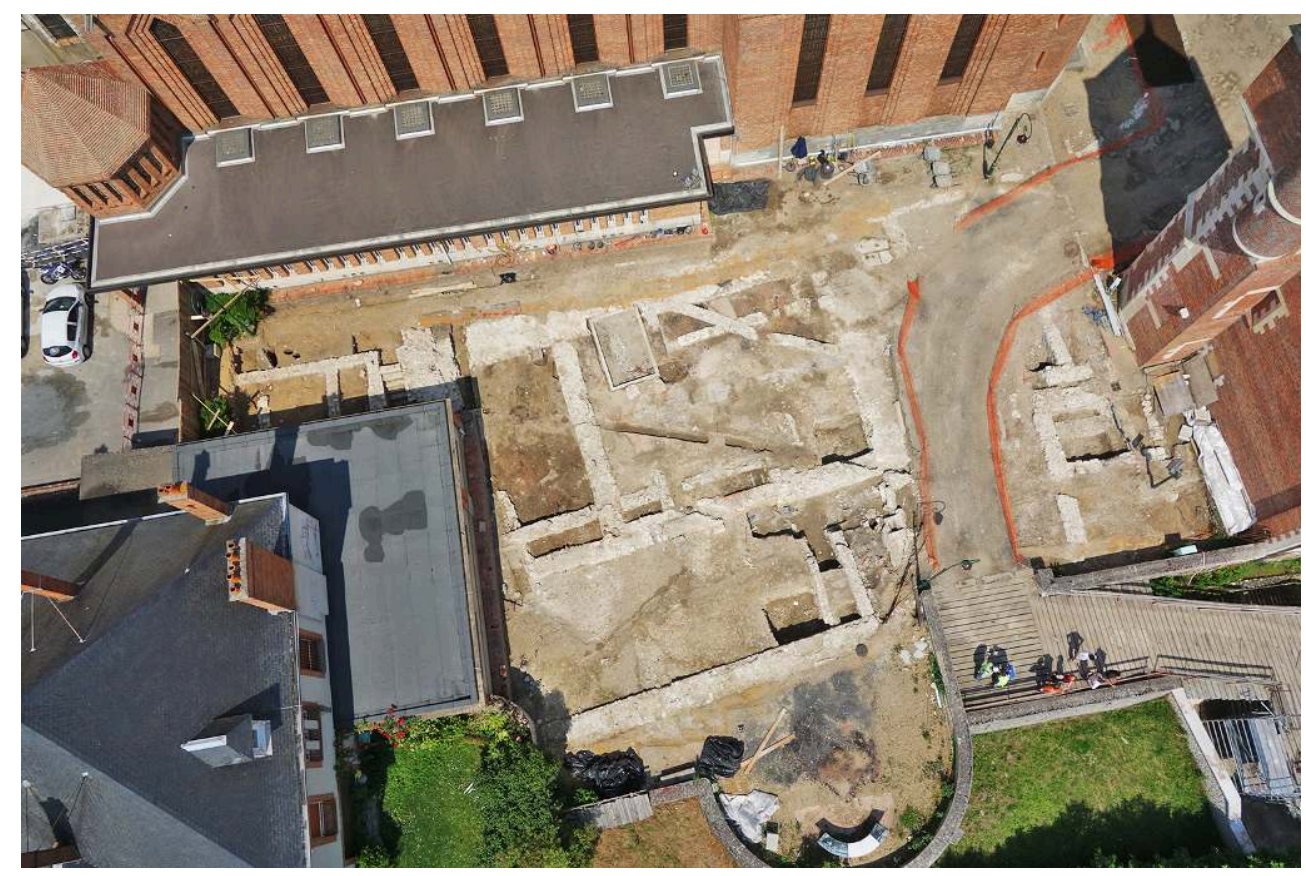

Cl. dép. du Loiret

L'aile occidentale ainsi dégagée complète le plan de la résidence royale de la fin du Moyen Âge (fig. 9). 
Fig. 9 - Gien, plan de l'aile ouest disparue

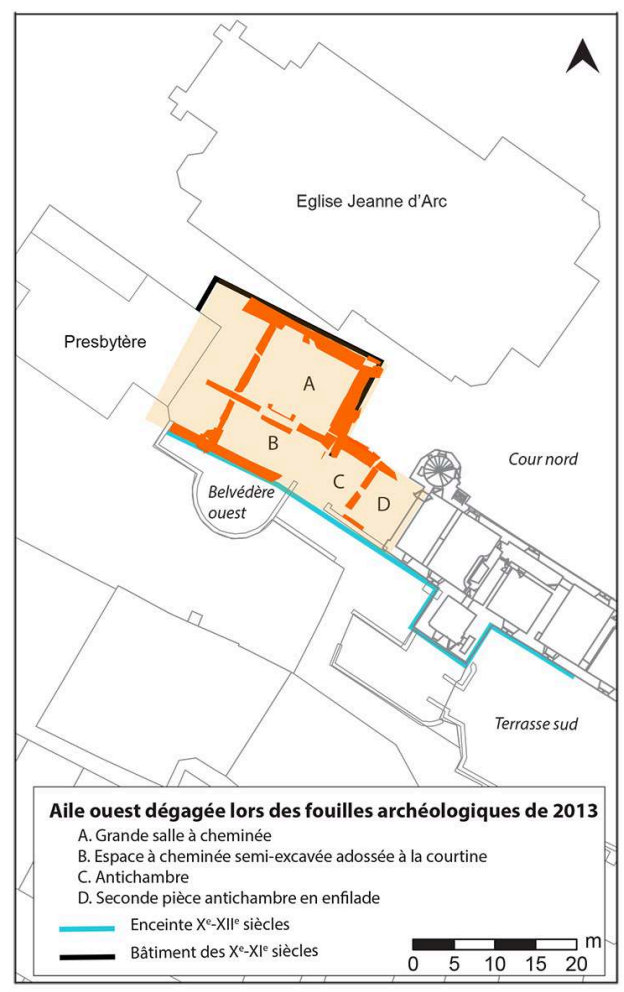

DAO M. Bizri

21 Ces bâtiments occidentaux (A, B, C et D) ont été arasés partiellement à la charnière du $\mathrm{XVIII}^{\mathrm{e}}$ et $\mathrm{du} \mathrm{XIX}^{\mathrm{e}}$ siècle, comme le suggère la chronologie $\mathrm{XV}^{\mathrm{e}}-\mathrm{XVIII}^{\mathrm{e}}$ siècle des nombreux éléments de destructions observés lors de la fouille archéologique, qui viennent combler les espaces inusités de l'aile ${ }^{26}$. Certains murs sont arasés pour faire place au chantier de la prison qui s'installe à la place de cette aile à partir de 1823, dès lors que le château accueille la sous-préfecture et le tribunal. Le pignon occidental du logis sud a été consolidé après la seconde guerre mondiale pour le dégager des bâtiments modernes qui lui était accolés, ruinés lors du bombardement de la ville en 1940. Cette reconstruction a entraîné un remontage partiel de la charpente du logis sud: une des travées de charpentes est plus longue que les autres et les marques de charpenterie sont en désordre. Cependant, elle forme bien une charpente complète, numérotée depuis l'est vers l'ouest. La datation des bois et leur phasage n'est, en revanche, pas remise en question pour la compréhension du chantier d'Anne de France.

La pièce principale (A) est une salle pavée de carreaux de terres cuites, qui comporte une large cheminée monumentale située sur le mur de refend au sud (fig. 10). 
Fig. 10 - Gien, vue en cours de fouilles de la grande salle de l'aile ouest disparue

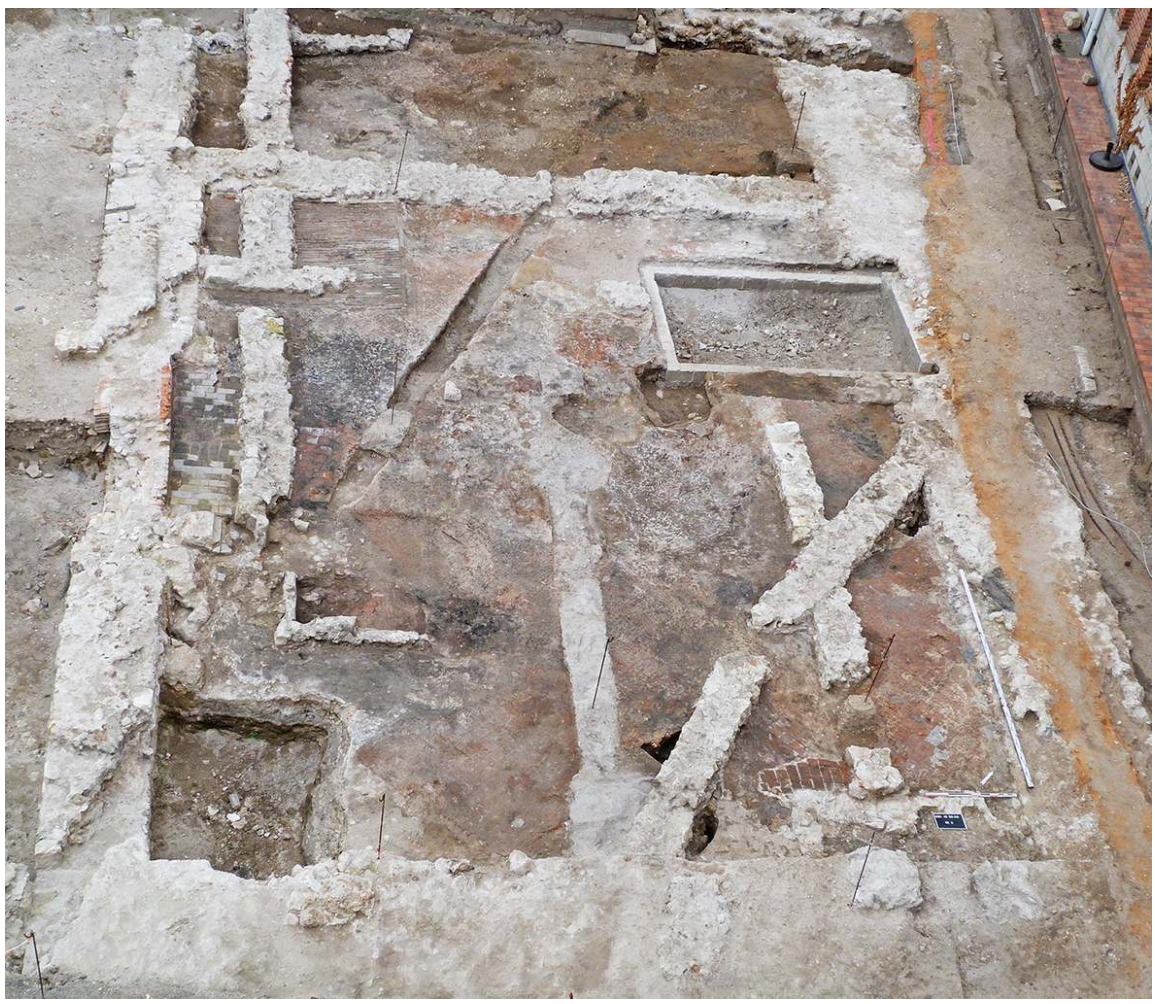

Cl. M. Bizri

23 L'installation de cette pièce pavée a arasé toute occupation de ce bâtiment comprise entre la fin du Xve et le Xvi ${ }^{e}$ siècle. Cette salle est la plus vaste du château (14 x $\left.12 \mathrm{~m}\right)$. Elle pouvait donc être dédiée à la représentation du pouvoir. La cheminée partage son conduit avec une seconde cheminée monumentale, située au revers, mais un deminiveau plus bas (fig. 11).

Fig. 11 - Gien, détail de la cheminée de la pièce $C$ adossée contre la courtine, aile ouest disparue

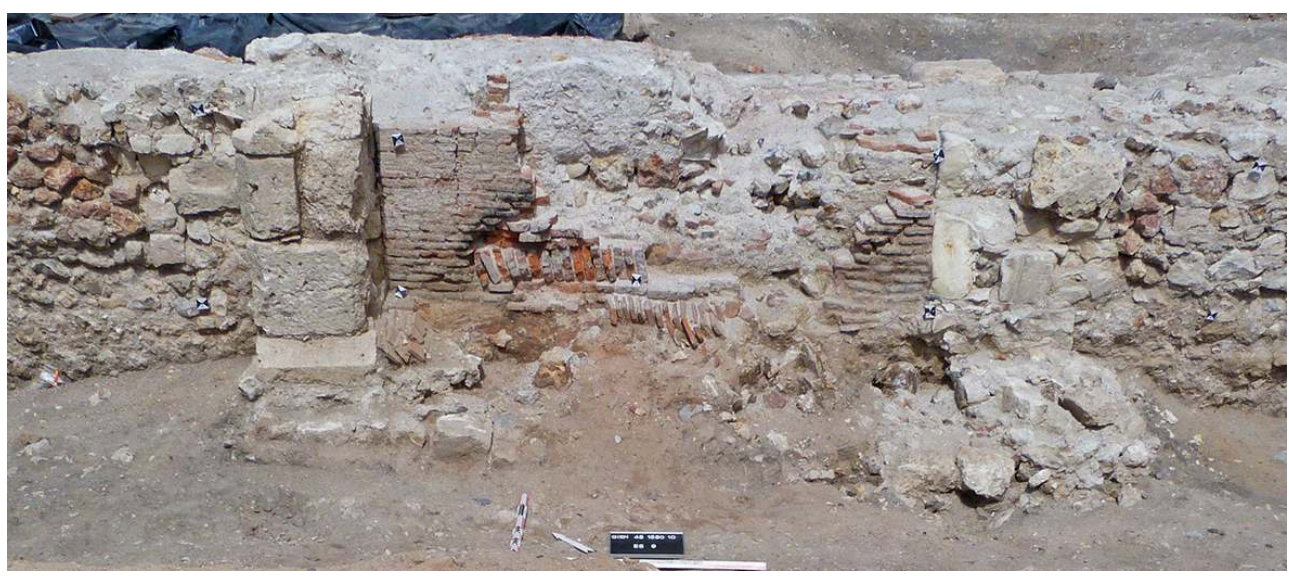

Cl. M. Bizri

24 On accède à ce niveau (C) par plusieurs marches aménagées depuis la petite pièce située en enfilade (B). L'accès à la pièce principale (A) n'a pu être déterminé en raison de l'arasement très prononcé des maçonneries. 


\section{Étape $1 \mathrm{~b}$ : les pièces $C$ et $D$ de l'aile disparue et la tour ouest (vers 1482)}

La présence des seuils conservés malgré les réfections sur le pignon ouest confirme la présence de deux étages, dont un sous-comble, desservis par la tour d'escalier ouest. Il est vraisemblable de considérer les pièces $C$ et $D$ et la tour ouest dans un ensemble de construction cohérent. Deux échantillons à aubier complet, prélevés dans la tourelle d'accès et dans la charpente de la chambre haute ouest du logis sud encore en élévation, indiquent un abattage des bois à l'automne-hiver 1481-1482. Cette phase d'abattage est également représentée dans la charpente du logis sud, datée de 1483, en tant que reste de stock inutilisé lors de l'étape $1 \mathrm{~b}$. Aussi, le pignon ouest comporte des seuils et ne semble pas constituer une véritable étape de chantier à la différence de ce qui a pu être observé pour les autres corps de logis. Ce constat accrédite l'hypothèse d'une mise en œuvre des bois pour les pièces $C$ et $D$ dès 1482 , voire un peu avant.

\section{Les autres étapes}

D'autres observations menées sur les murs pignons des différents corps de bâtiment du château documentent la progression du chantier de construction vers l'ouest. Le logis sud, en effet, comporte dans les combles, au niveau des entraits de charpente, le décor d'une croix en brique noire sur sa face orientale (fig. 12).

Fig. 12 - Gien, détail de la croix vernissée du premier pignon, vue intérieure et du rampant du pignon sur la toiture

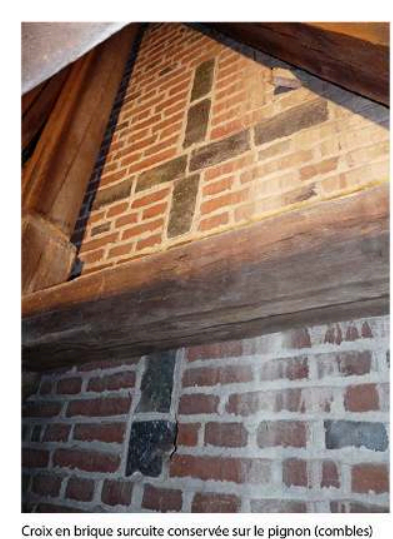

Croix en brique surcuite conservée sur le pignon (combles) situé entre le logis sud et le logis de l'oriel

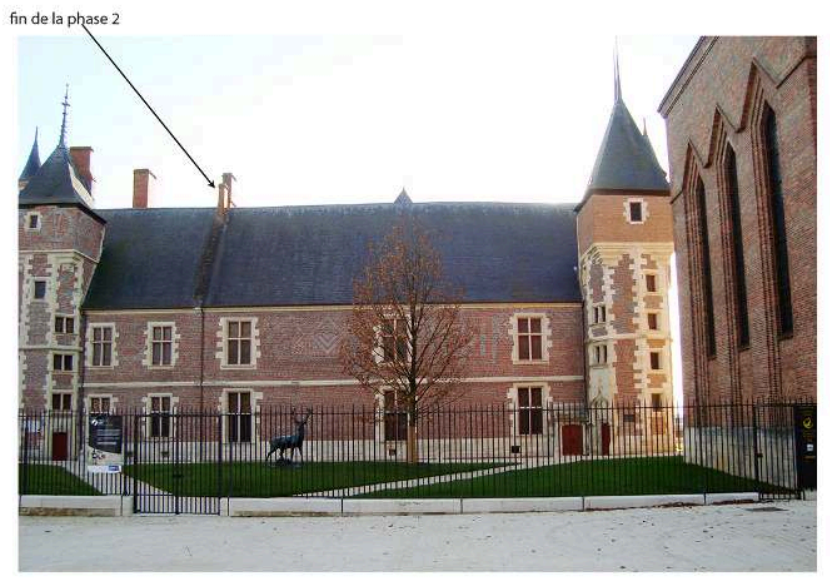

Cl. M. Bizri

La position de ce motif oblige à voir dans ce mur un ancien mur-pignon extérieur, comme le confirme la petite baie en plein-cintre placée à gauche de la croix et la présence d'un demi-rampant en pierre dépassant des toitures sur le versant nord. Ce mur-pignon marque une étape dans la progression du chantier vers l'ouest (étape 2), étape confirmée à la fois par la singularité des charpentes et leur datation (fig. 13). 
Fig. 13 - Gien, charpentes de l'aile sud en coupe transversale (schématique), contreventement et marques d'assemblage

Charpentes de l'aile sud en coupe transversale, contreventement et marques d'assemblages. Cèdre 2014.
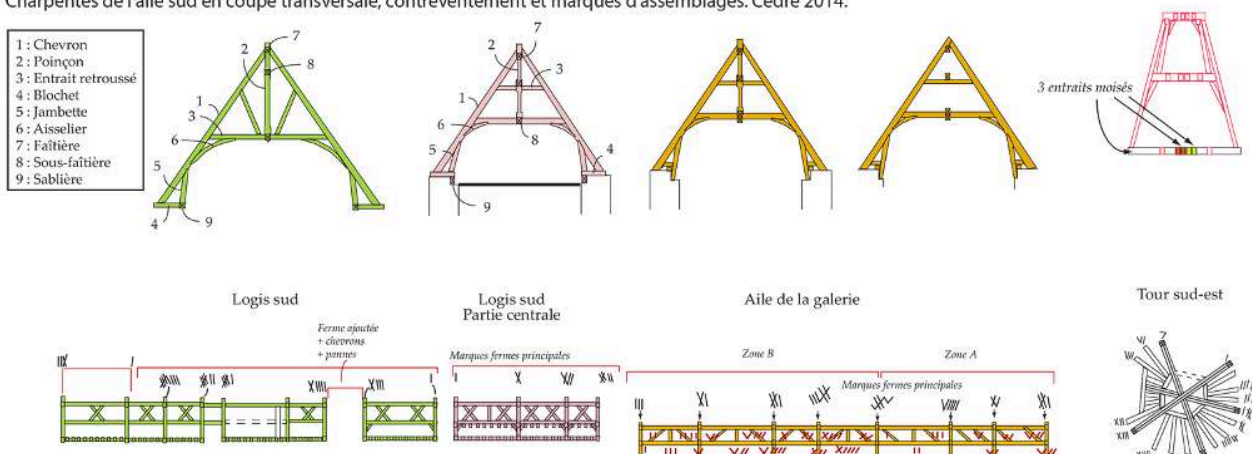

Logis sud
Partie centrale

Aile de la galerie

Tour sud-est
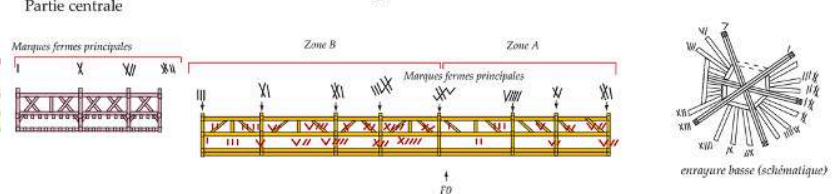

DAO C. Perrault

Un petit corps de logis court s'accole dans son prolongement. Il comporte en face sud un oriel se développant à l'origine sur deux niveaux (fig. 14).

Fig. 14 - Gien, logis de l'Oriel
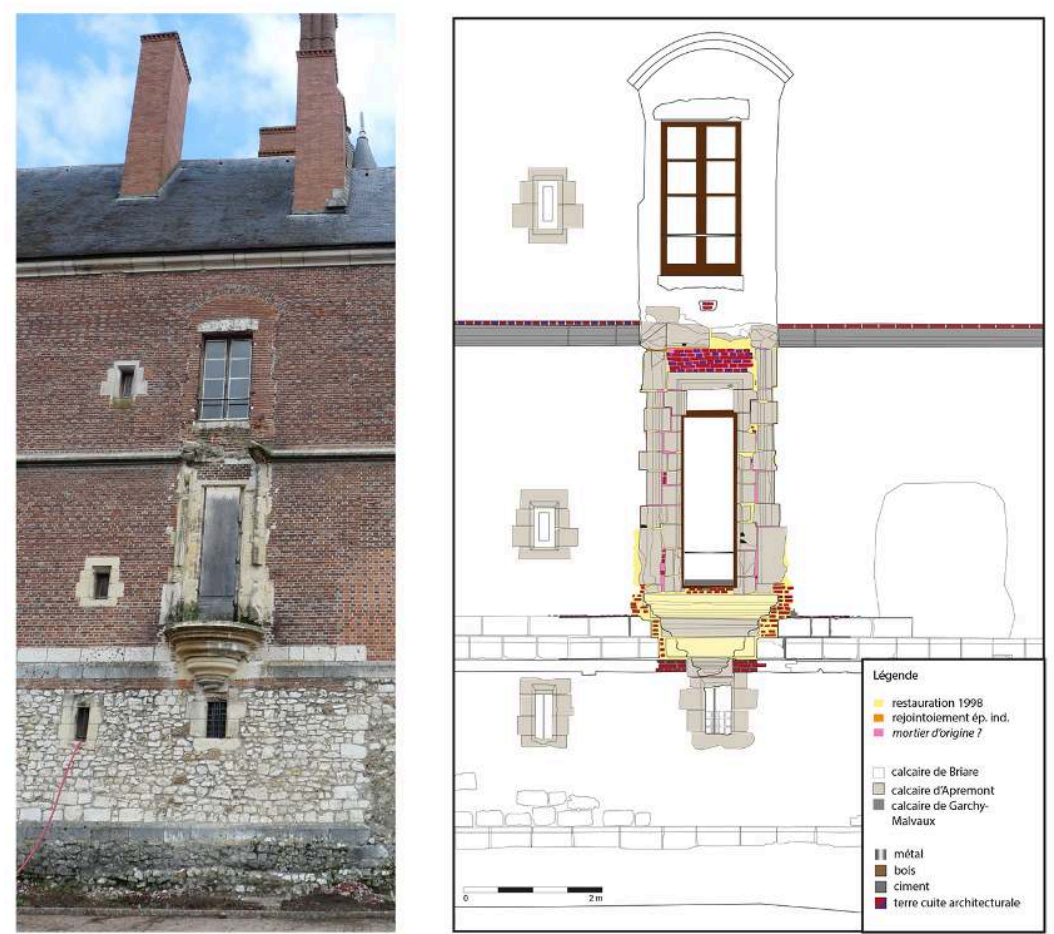

Gien, oriel (balcon) de la façade sud, avant les restaurations de 2014

Cl. et DAO M. Bizri

L'usage d'un appareil de brique au décor de losanges noirs ainsi qu'une petite baie rectangulaire, bouchée pour l'installation du corps de galerie, prouvent que le mur occidental de ce logis constituait un mur-pignon (fig. 15). 
Fig. 15 - Gien, détail du second pignon (logis de l'Oriel), vue intérieure

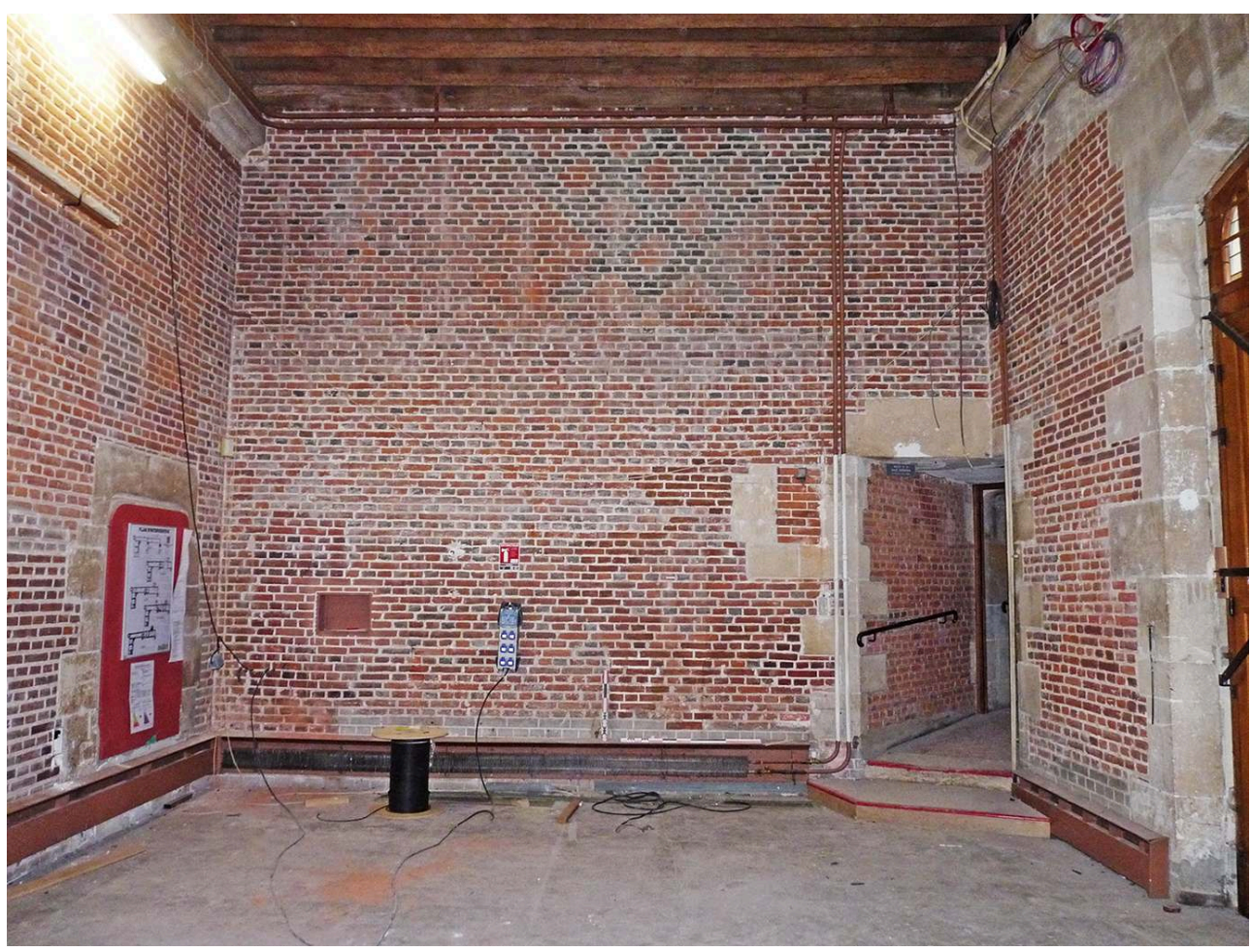

Cl. M. Bizri

30 La porte insérée en biais dans ce mur est une ouverture postérieure, comme l'indique la différence de niveau (une marche de $0,30 \mathrm{~m}$ ). Elle mène de la galerie à la tour d'escalier pour raccorder la circulation de ce corps nouvellement construit (étape 3) au logis sud préexistant.

31 Plusieurs éléments confirment ensuite que le corps de galeries et le logis oriental sont le fait d'une même campagne de construction, qui se déroule rapidement (étapes 4 et 5). Les fenêtres de ces deux ensembles présentent la même mouluration (un tore simple) et l'escalier, situé dans l'angle, dessert de manière cohérente le logis et la galerie par des marches palières précédant les portes de chaque niveau.

\section{Table-rase du passé architectural du lieu?}

32 Un plan de la fin du XVIII ${ }^{\mathrm{e}}$ siècle représente plusieurs enceintes entourant la ville de $\mathrm{Gien}^{27}$, dont une ceignant le promontoire du château et incluant l'église (fig. 16). 
Fig. 16 - Gien, plan schématique de la ville à la fin du XVIII ${ }^{\mathrm{e}}$ siècle, route d'Orléans à Briare

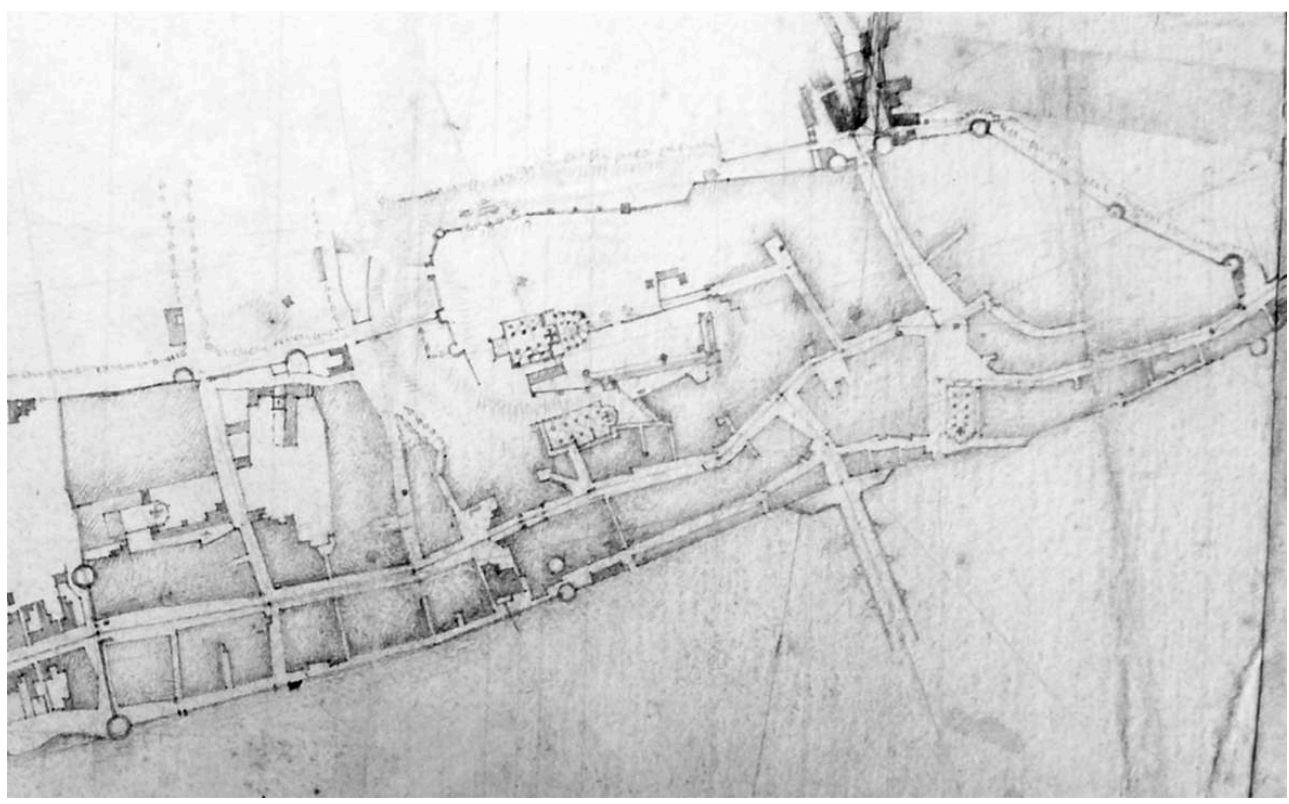

Sans échelle connue

Archives dép. du Loiret, série C, suppl. 5.

Cl. dép. du Loiret.

Bien que schématique, le tracé de cette enceinte haute a pu être confirmé par les opérations archéologiques au nord-ouest ${ }^{28}$ et au sud, alors que les espaces d'aujourd'hui ne laissent deviner aucun vestige (fig. 17).

Fig. 17 - Gien, restitution du tracé de l'enceinte médiévale du promontoire

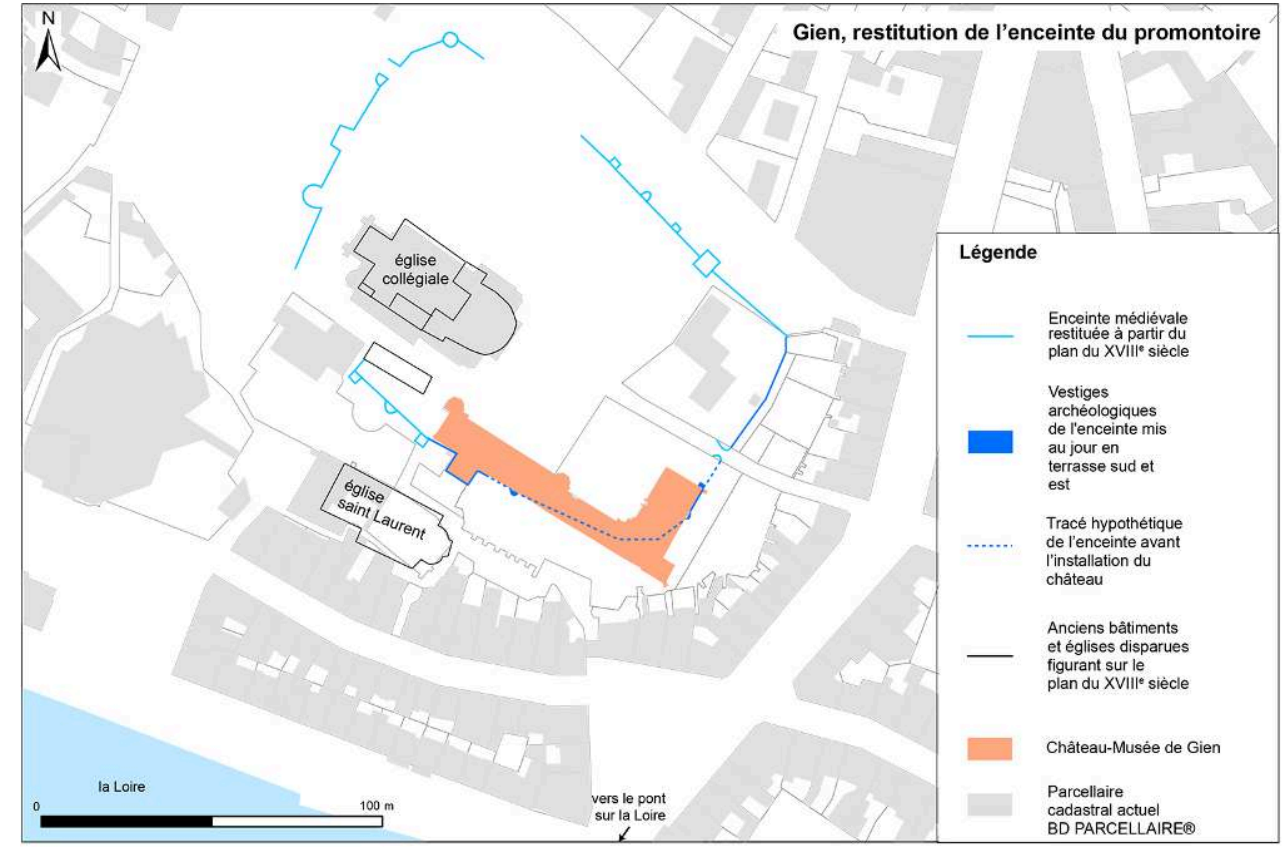

DAO M. Bizri

L'environnement immédiat du château médiéval sur le promontoire est très peu connu, hormis une maison, dite du chanoine, actuellement encore en élévation ${ }^{29}$. Une partie de 
la courtine sud du promontoire a été dégagée sur le belvédère ouest lors des fouilles archéologiques de 2013, laissant apparaître un appareil soigné de petits moellons de calcaire, dans une chronologie relative qui la place au plus tôt à la fin $\mathrm{du} \mathrm{x}^{\mathrm{e}}$ ou au début du XI ${ }^{e}$ siècle $^{30}$.

Une petite tour semi-circulaire, appartenant également à la courtine médiévale et non représentée sur le plan du XVIII ${ }^{\mathrm{e}}$ siècle, a été mise au jour au pied des logis est et ouest. Arasé, ce vestige est conservé dans le soubassement calcaire du logis, par la mise en place d'un arc de décharge. Un seul tesson de céramique découvert dans le comblement de cette structure signale le début du Moyen Âge ( $\mathrm{xI}^{\mathrm{e}}-\mathrm{XII}{ }^{\mathrm{e}}$ siècles).

Côté nord-est, l'enceinte apparaît dans le soubassement de l'aile est. Elle barrait ce flanc du promontoire suivant un tracé que l'on retrouve sur le parcellaire en poursuivant le rebord du promontoire vers le nord. En revanche, entre le logis de l'Oriel et le retour nord de l'enceinte, cette enceinte a complètement disparue avec la construction des logis d'Anne de France.

Peu de vestiges accessibles renseignent sur l'organisation de l'enceinte et de l'espace castral avant l'installation des logis de la fin $d u x^{e}$ siècle. Les travaux de la fin du $\mathrm{xV}^{\mathrm{e}}$ siècle ont aussi profondément remodelé le rebord du promontoire: un apport massif d'argile a été constaté lors des fouilles. Il vient compenser la pente du coteau dans l'angle sud-est pour asseoir la tour ronde plus en avant vers la Loire.

Le logis sud comprend deux salles voûtées d'ogives, espaces semi-excavés pourvus de soupiraux en abat-jour. Ils ont d'abord été compris comme les potentiels vestiges d'un édifice antérieur au château d'Anne de France à cause de la facture des voûtes. Toutefois, les datations dendrochronologiques des planchettes de coffrage piégées dans les voûtains ont réfuté cette hypothèse, les rendant contemporains de la construction des logis par Anne de France ${ }^{31}$. Des vestiges de maçonneries d'édifices antérieurs ont toutefois été rencontrés lors de sondages archéologiques ponctuels aux abords du soubassement sud du logis sud et à l'aplomb du pignon est du logis de l'Oriel. Ils mettent en évidence des maçonneries de moellons de calcaire liés au mortier - 1,90 m à 2,20 m environ de large -, antérieures aux logis d'Anne de France. Il n'est pas possible de relier ces éléments entre eux. L'épaisseur des maçonneries rencontrées ne s'explique pas seulement par la nécessité de rendre solide la semelle de fondation pour porter les deux étages en brique du logis, par ailleurs de faible épaisseur - environ $1 \mathrm{~m}$ de large et en matériau plus léger que le calcaire. On suppose donc, de manière vraisemblable, qu'elles appartiennent à un édifice antérieur. L'existence d'édifices antérieurs était soupçonnée par la présence de maçonneries qui s'insèrent maladroitement dans le soubassement calcaire du logis sud, à l'angle oriental formé avec la tour Jeanne d'Arc. Ces éléments de maçonneries antérieures s'implantent dans une orientation différente $\mathrm{du}$ soubassement des logis. Ils sont vraisemblablement à mettre en rapport avec le bâtiment rectangulaire fouillé du belvédère ouest (pièces $A$ et $B$ ), qui observe un désaxement similaire (cf. fig. 9 , trait plein noir). Les pièces $A$ et $B$ de ce bâtiment s'installent, en effet, sur un bâtiment médiéval préexistant du $\mathrm{x}^{\mathrm{e}}$ siècle $^{32}$.

La tour Jeanne d'Arc se développe en saillie de l'ancienne enceinte ${ }^{33}$ (fig. 18). 
Fig. 18 - Gien, tour Jeanne d'Arc après les restaurations de 2014

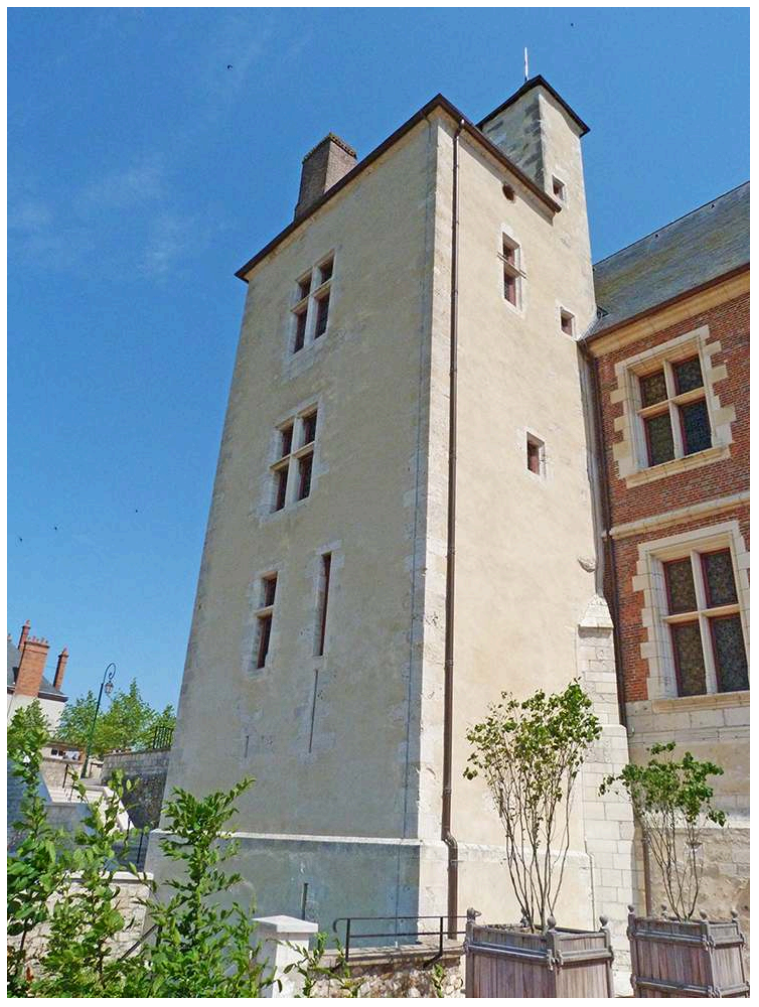

Cl. M. Bizri

40 Cette tour quadrangulaire $(6,30 \times 7,90 \mathrm{~m})$ est construite en maçonnerie de rognons de silex noyés dans un mortier très sableux ${ }^{34}$, aux chaînes d'angles taillées en calcaire lacustre de Briare. Elle se compose de cinq niveaux : un premier niveau presque plein, inaccessible aujourd'hui, un autre correspondant au rez-de-chaussée haut des logis, puis deux étages, et, enfin, un niveau de combles non aménagés. L'accès au niveau du rez-de-chaussée haut et au premier étage s'effectue depuis les logis. Le dernier étage et le niveau de combles sont desservis par une tourelle d'escalier en vis, semi-hors-œuvre, aménagée dans un des angles rentrant de la tour, à sa jonction avec le logis sud, en façade sud.

41 L'analyse du bâti de la tour permet de dégager quatre états pour l'époque médiévale. La base conserve deux ressauts de fondations. Le premier est aveugle et sert d'assise au second portant deux archères, aujourd'hui condamnées. Ces fentes d'archères sont tronquées par des ouvertures médiévales plus tardives, d'une taille restituable d'au moins 1,50 $\mathrm{m}$ de haut pour $0,06 \mathrm{~m}$ de large. Elle se placent au plus tôt dans la seconde moitié $\mathrm{du} \mathrm{XII}^{\mathrm{e}}$ siècle, sans que le $\mathrm{XIII}^{\mathrm{e}}$ siècle ne puisse être totalement exclu ${ }^{35}$. Deux campagnes d'aménagement résidentiel et de confort sont réalisées entre la fin du $\mathrm{XIII}^{\mathrm{e}}$ siècle et le début $\mathrm{du} \mathrm{XV}^{\mathrm{e}}$ siècle. Des petites fenêtres rectangulaires chanfreinées sont ouvertes sur les façades et des latrines et des cheminées équipent les pièces intérieures de la tour. Puis, les fenêtres des niveaux 3 et 4 de la tour sont reprises avec l'installation de fenêtre à meneau à moulures en cavets ${ }^{36}$. Enfin, la tour est raccordée aux logis sud lors du chantier d'Anne de France (fig. 19). 
Fig. 19 - Gien, tour Jeanne d'Arc, coupe sud-nord des élévations

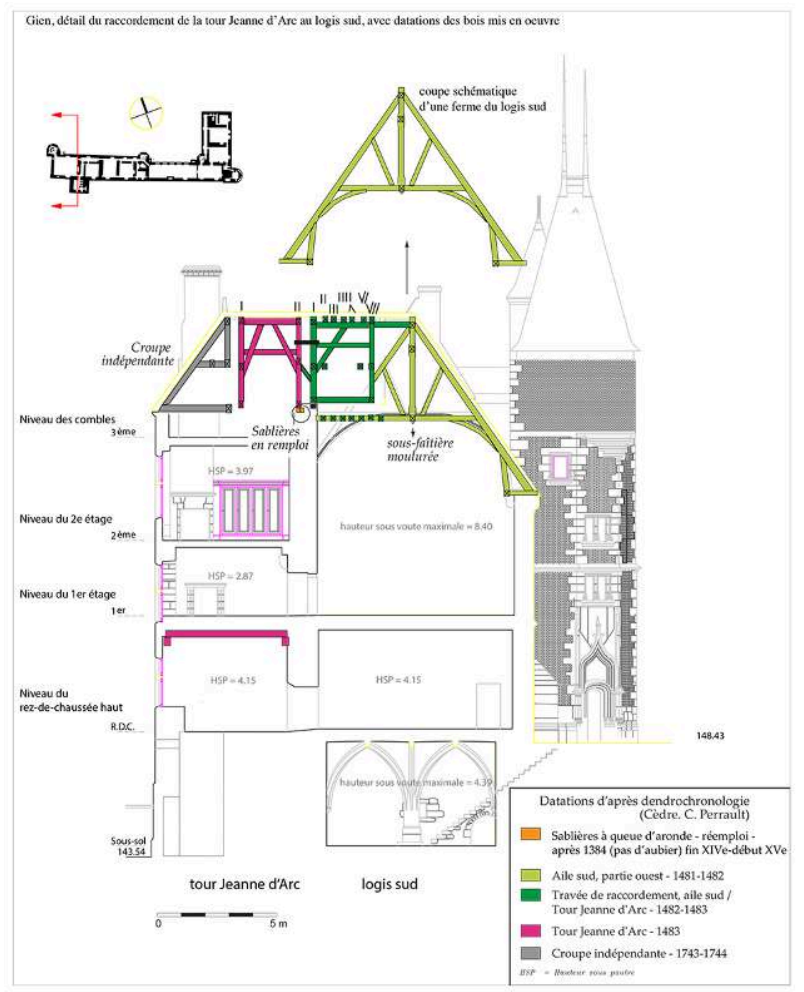

DAO M. Bizri et C. Perrault

42 Le niveau 1 de la tour est condamné et le niveau 2 partiellement remblayé ; un espace servant de fosses-latrines est toutefois ménagé au droit des fondations. Un sol créé dans la tour est mis de niveau avec celui du rez-de-chaussée haut des nouveaux logis s'étendant au nord. En outre, le plafond de cette pièce est surhaussé d'environ un mètre, agrandissant ainsi la volumétrie de la pièce originelle de la tour, afin d'obtenir une hauteur équivalente (soit $4,15 \mathrm{~m}$ ) à celles des pièces du nouveau logis. Deux fenêtres sont aménagées en façade sud pour l'éclairer. Elles se distinguent des fenêtres à meneau des niveaux supérieurs, conservées de l'état précédent avec quelques reprises limitées. Le dernier niveau est abaissé. À cette occasion, une ouverture est bouchée et tronquée et une noue de raccordement est créée afin d'articuler la toiture aux nouveaux logis disposés au nord. La charpente enjambe le mur nord de la tour Jeanne d'Arc, sur lequel est installée une sablière pour la recevoir ${ }^{37}$. Le dernier niveau de la tour ne trouvant pas de correspondance dans les logis, la circulation par la tourelle d'escalier (face est) est donc conservée pour en permettre l'accès.

Ainsi, lorsque le chantier du château s'achève, le promontoire a été totalement remanié. . Seuls quelques bâtiments dont la tour Jeanne d'Arc et probablement l'aile ouest, derrière la courtine, signalent l'ancienneté du site. Ils laissent place à une nouvelle résidence dans un environnement restructuré.

L'articulation des logis du château avec l'église-collégiale, détruite et reconstruite à plusieurs reprises, n'a pas pu être mise en évidence ${ }^{38}$. Si la tour-clocher de la collégiale médiévale est conservée, le chœur, entièrement repris par des travaux engagés par Anne de France, n'est plus visible actuellement ${ }^{39}$. 


\section{Des choix constructifs hérités du goût de Louis $\mathrm{XI}$ : l'usage de la brique}

L'élévation des murs des logis d'Anne de France est constituée majoritairement de briques cuites à surcuites, liées au mortier de chaux et reposant sur un soubassement calcaire. Plusieurs décors géométriques (losanges, cercle et réseaux) apparaissent ainsi par un jeu sur la polychromie issue de la cuisson des briques (fig. 20).

Fig. 20 - Gien, tour d'escalier nord

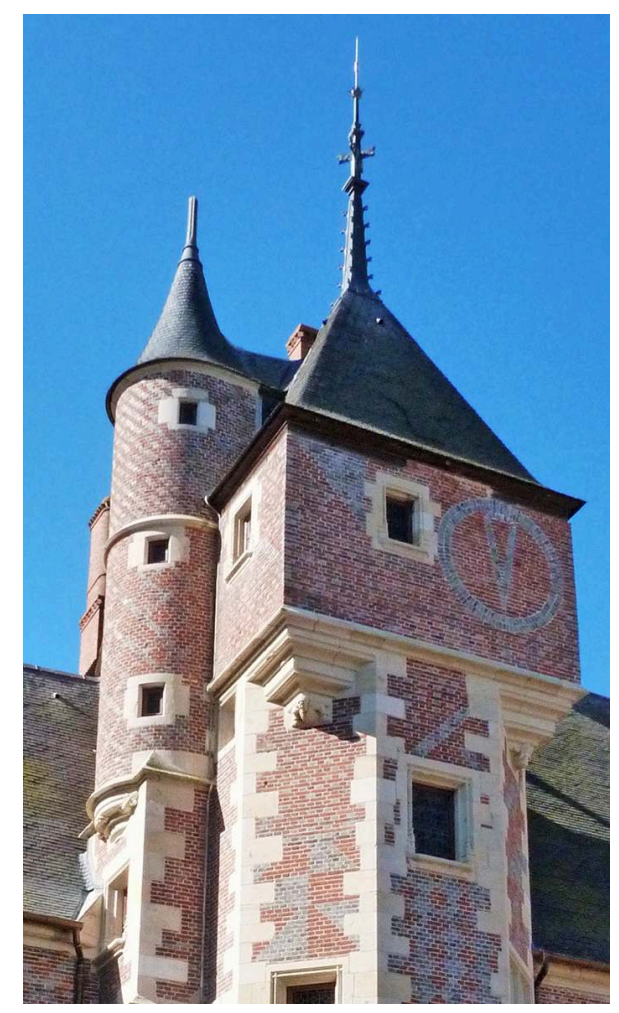

Cl. M. Bizri

Les façades ne sont pas encore rythmées comme à Blois par des contreforts en pierres calcaires - aile Louis XII, qualifiée de neuve en 1510. À Gien, l'horizontalité des ailes est soulignée par un bandeau calcaire servant de larmier - mouluration de tore à jet d'eau -, marquant les changements de niveaux. Le traitement des ouvertures est sobre: les fenêtres à croisée comportent des bases prismatiques, avec quelques nuances de traitement accompagnant la progression du chantier. Sauf pour le soubassement, le calcaire des ouvertures choisi est le calcaire d'Apremont-sur-Allier, calcaire argileux gris clair à jaune : l'emplacement de Gien en rive de Loire facilite l'accès à ce matériau qui voyage par transport fluvial depuis le $\operatorname{sud}^{40}$. Le décor sculpté est présent uniquement sur les tours d'escalier et l'oriel - personnages ou animaux réels ou légendaires.

Le module des briques mises en œuvre à Gien $-21 / 22 \mathrm{~cm} \times 10 / 11 \mathrm{~cm} \times 4 / 5 \mathrm{~cm}-$ correspond à un gabarit de production invariable, que l'on retrouve dans les constructions modernes jusqu'au $\mathrm{xx}^{\mathrm{e}}$ siècle en Sologne $\mathrm{e}^{41}$. À Blois, la construction des latrines de l'aile Louis XII offre un gabarit proche $(22 \times 5,5 \times 5 \mathrm{~cm})^{42}$. Les lieux de 
production et/ou d'extraction de l'argile pour la période médiévale n'ont pas encore été identifiés autour de Gien, ou ailleurs dans la région, mais sont un peu mieux connus pour la Sologne aux époques moderne et contemporaine ${ }^{43}$. Des puits d'extraction d'argile étaient situés à Arrabloy (limite nord de la feuille), à l'est de la forêt de SaintBrisson - les Maisons Brûlées, le Pozoir - et à Autry - la Taille aux Chats, le Petit SaintGondon. Leur chronologie de fonctionnement n'est cependant pas précisée ${ }^{44}$.

Le choix de la brique est un parti-pris pour le couple régent. Ce matériau est couramment employé dans les constructions royales de Louis $\mathrm{XI}^{45}$. On le retrouve ainsi à Amboise - tour du Garçonnet initiée vers 1463 avec deux corps de logis, aujourd'hui disparus ${ }^{46}-$, au Plessis-lès-Tours vers $1478-1480^{47}$, dans l'hôtel que Louis XI fait édifier vers 1479-1480 à Orléans ${ }^{48}$ - la "Maison du Roi ", place Saint-Aignan -, et même à Auxonne au cœur du territoire bourguignon ${ }^{49}$. Au Plessis-lès-Tours, ce matériau est utilisé dans la construction du logis du «Petit Bourbon » dédié à la résidence de Pierre et Anne. Aucun compte ne renseigne sur les ouvriers ou architectes sollicités pour l'édification du château de Gien. Étant donné le synchronisme des constructions du Plessis-lès-Tours et de la «Maison du roi " à Orléans, auquel on peut désormais rattacher Gien, il est possible d'évoquer l'itinérance des ouvriers et de leur savoir-faire, dans ces différents chantiers royaux du Val de Loire (cf. fig. 4). Ce choix de la brique inscrit les époux de la Régence dans la continuité de l'œuvre constructive de Louis XI, œuvre qu'ils prolongent également sur le plan politique ${ }^{50}$. Remanier quasiment en totalité la résidence médiévale antérieure constitue, en effet, une rupture visuelle avec le passé, notamment le passé soumis aux influences bourguignonnes. Cette opération peut donc faire écho au rôle de Louis XI dans la liquidation de la principauté bourguignonne, limitrophe du territoire giennois, rattachée à la couronne en 1477, au terme d'une longue période de tensions avec la royauté.

\section{Des expérimentations avec les superstructures en bois}

49 Le chantier de construction s'étend sur une petite dizaine d'années et il est donc possible de déceler des tâtonnements et expérimentations constructives.

\section{Les chambres hautes}

50 La tour ouest et sa chambre haute sont une expérimentation du début de chantier. Les deux échantillons avec aubier de la charpente de la tourelle d'escalier, menant à la chambre haute, et de l'un des aisseliers à culot sculpté de cette même tourelle donnent un abattage en automne-hiver 1481-1482 (fig. 21). 
Fig. 21 - Gien, aisseliers sous l'enrayure de la tourelle d'accès à la chambre haute de la tour ouest et détail d'un culot sculpté recevant un aisselier
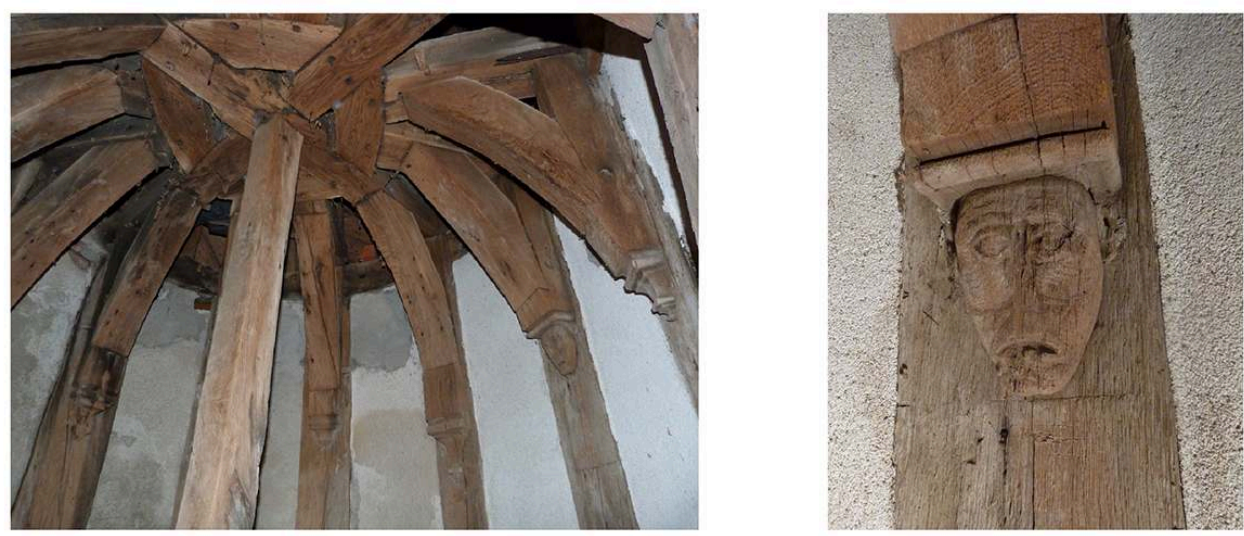

Cl. M. Bizri et C. Perrault

51 De plan quadrangulaire, le mur oriental de la chambre est placé sur l'un des murs à pans coupés du fût de la tour d'escalier polygonale, ce qui peut paraître maladroit, voire fragiliser la stabilité de la superstructure (fig. 22).

Fig. 22 - Gien, tour d'escalier ouest

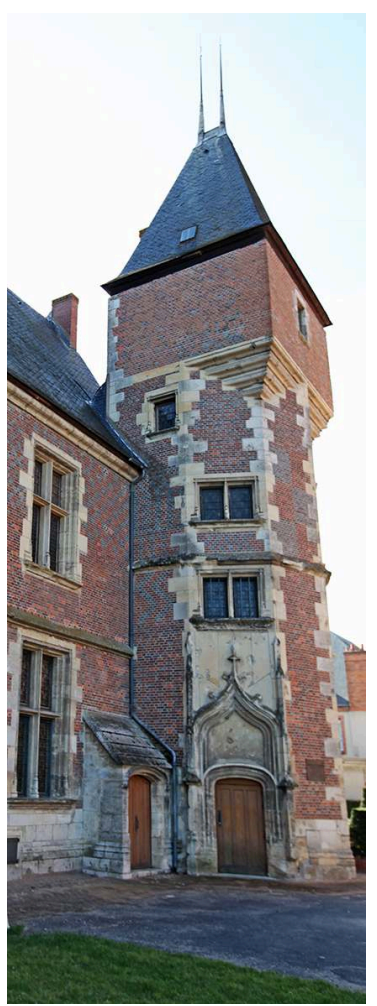

Cl. S. Marchant

La conception des chambres hautes sur escalier est perfectionnée dans les deux autres tours d'escaliers à chambre haute du château. Le passage du plan à pan coupé de la tour d'escalier au plan quadrangulaire de la chambre s'insère moins maladroitement dans les toitures des chambres nord et ouest. 

comprises, le sens de la vis est différent des autres tours d'escalier du château. Elle permet, notamment, comme déjà mentionné plus haut, l'accès aux niveaux supérieurs de la tour Jeanne d'Arc ou de l'aile ouest disparue. Cette tour constitue l'escalier d'honneur, sa largeur ainsi que le décor sculpté surmontant la porte le confirment - arc en accolade à choux frisés, aujourd'hui très dégradés. La charpente de la tourelle d'escalier, donnant accès à la chambre haute, comporte des aisseliers reposant en pied sur des culots sculptés que l'on ne retrouve pas dans les autres tours (cf. fig. 21). Bretagne dès le XIv ${ }^{\mathrm{e}}$ siècle $^{51}$. La tour de Jean sans Peur à Paris en comporte une du début $\mathrm{du} \mathrm{xv}^{\mathrm{e}}$ siècle $^{52}$. De nombreux édifices présentant des chambres carrées sur tour d'escalier ont été également recensés dans la Nièvre, à la charnière des $\mathrm{xv}^{\mathrm{e}}$ $\mathrm{xVI}^{\mathrm{e}}$ siècles $^{53}$. Si le château du Plessis-lès-Tours de Louis XI comporte bien une chambre haute accessible par un escalier, à Gien, la pièce est individualisée : elle couronne la vis de l'escalier et se détache de la tour.

L'élévation de la chambre haute de la tour nord a pu être approchée de manière plus précise. Le parement de brique comporte un décor présent sur deux faces, qui ne laisse pas présager l'ossature en bois interne présente au revers (fig. 23).

Fig. 23 - Gien, structure à ossature bois de la chambre haute de l'escalier de la tour nord

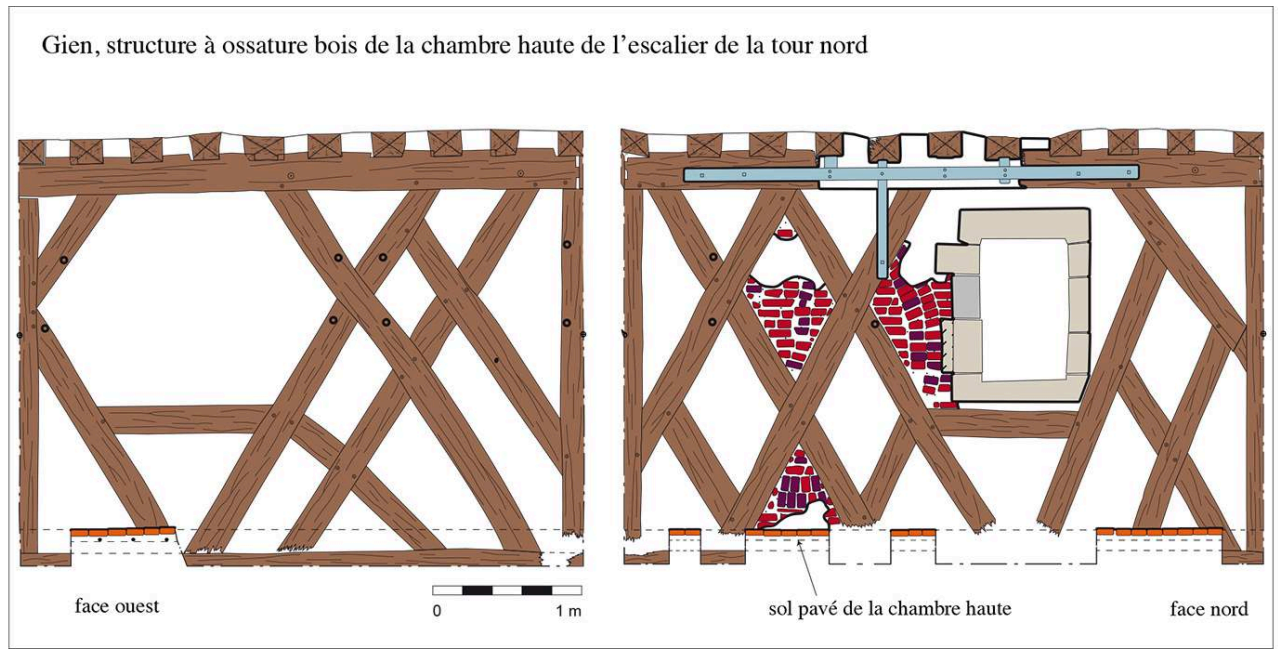

DAO dép. du Loiret

56 L'ossature de pièces obliques (décharges et guettes) entrecroisées s'insère par des mortaises dans les sablières de plafond et de chambrée. Elle forme un réseau de losanges, dont les pièces sont assemblées entre elles à mi-bois, maintenues par des chevilles. Les poteaux corniers sont constitués d'une pièce de bois évidée en équerre, facilitant la liaison des pans au changement d'angle. Certaines pièces obliques et un poteau présentent de petits creusements circulaires. Ils peuvent avoir reçu des chevilles d'appui pour la mise en place d'une étagère.

Le revêtement de brique du pan de bois est ainsi à la fois le parement extérieur de l'élévation, comprenant un décor, et le hourdis de l'armature. Il est large de vingtdeux centimètres, soit une longueur de brique. L'ossature de bois renforce la stabilité de l'ensemble en reportant le poids de la couverture et de la charpente sur les 
maçonneries de la tour, pour soulager le remplissage de brique qui recouvre intégralement la face extérieure des pans de bois et développe de grands motifs géométriques.

\section{Les charpentes}

58 Même si elles sont construites sur une période de quelques années, les charpentes de Gien dévoilent des singularités, qui montrent bien, avec les différentes séries de marquage des assemblages, la division du chantier en tranches de travaux (cf. fig. 13).

Les charpentes à chevrons formant fermes de l'aile sud (vers 1483) présentent des similitudes dans leur conception, avec comme principales caractéristiques l'absence d'entraits, des poinçons courts adaptés à l'aménagement des combles, attesté par les lucarnes et les cheminées, une forme arquée des jambettes, des aisseliers et des chevrons sous le niveau d'entraits retroussés. Dans le logis ouest de l'aile sud, des contrefiches raidissent la partie supérieure des chevrons. Dans ce même logis (vers 1483) et celui comportant l'oriel (vers 1486, cf. fig. 6 et 7), les entraits retroussés sont constitués de deux butons assemblés latéralement à tenon-mortaise au cours inférieur des sous-faîtières (fig. 24).

Fig. 24 - Gien, sous-faîtière inférieure de la charpente du corps de galerie constituée de deux pièces superposées rapprochées par une clef en bois (prisonnier) non visible, mais maintenue en place par deux chevilles

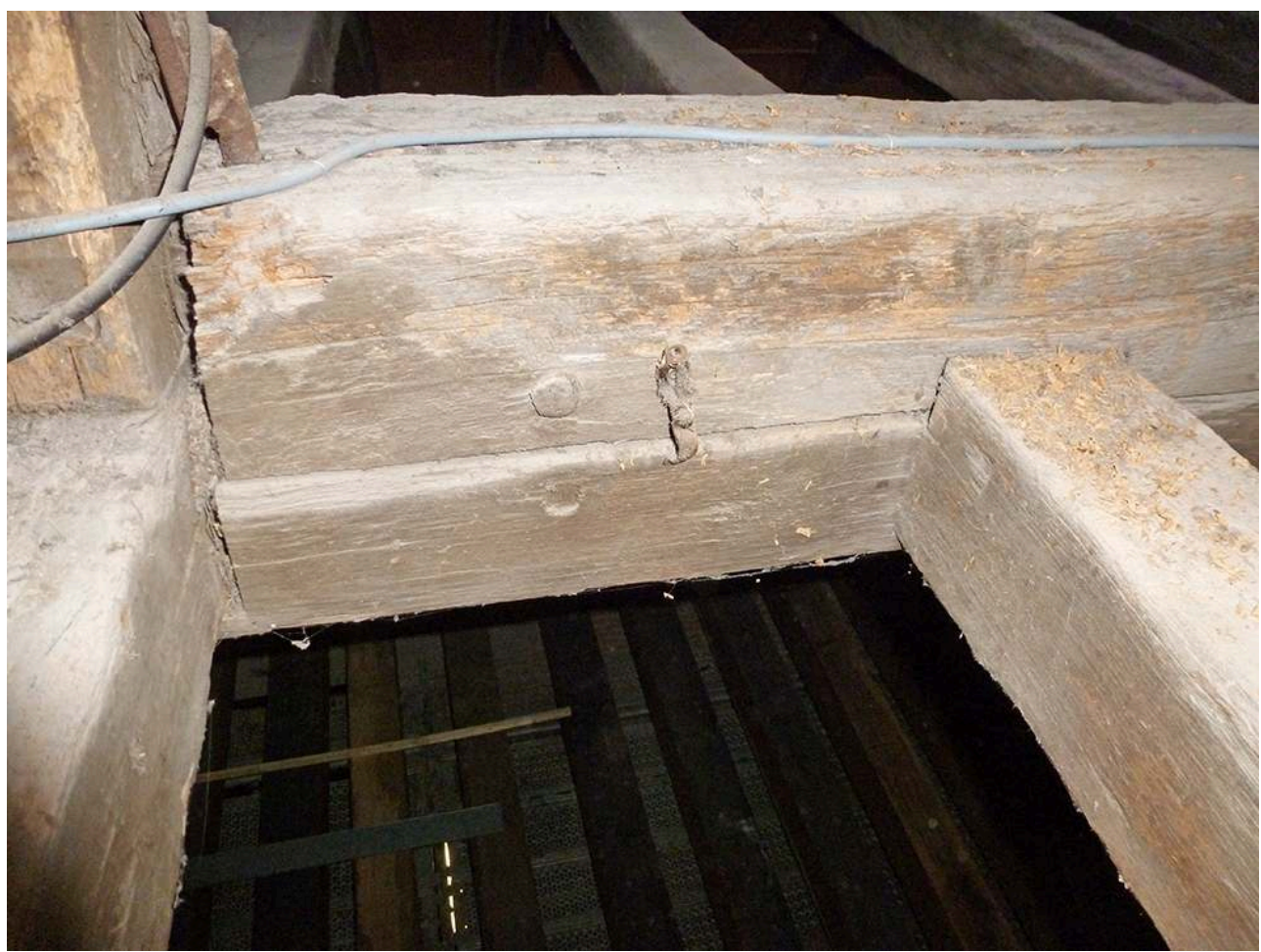

Cl. C. Perrault

Ce type d'assemblage est connu dès le XIV siècle sur une maison romane de Beaulieulès-Loches ${ }^{54}$. Il est largement diffusé au Xvi ${ }^{\mathrm{e}}$ siècle.

61 Dans le corps de galerie (vers 1490), le cours inférieur des sous-faitières est constitué de deux liernes superposées (fig. 25). 
Fig. 25 - Gien, vue de la charpente du corps de galerie (est) avec les faux-entraits en deux éléments assemblés latéralement aux liernes du niveau inférieur de sous-faîtage

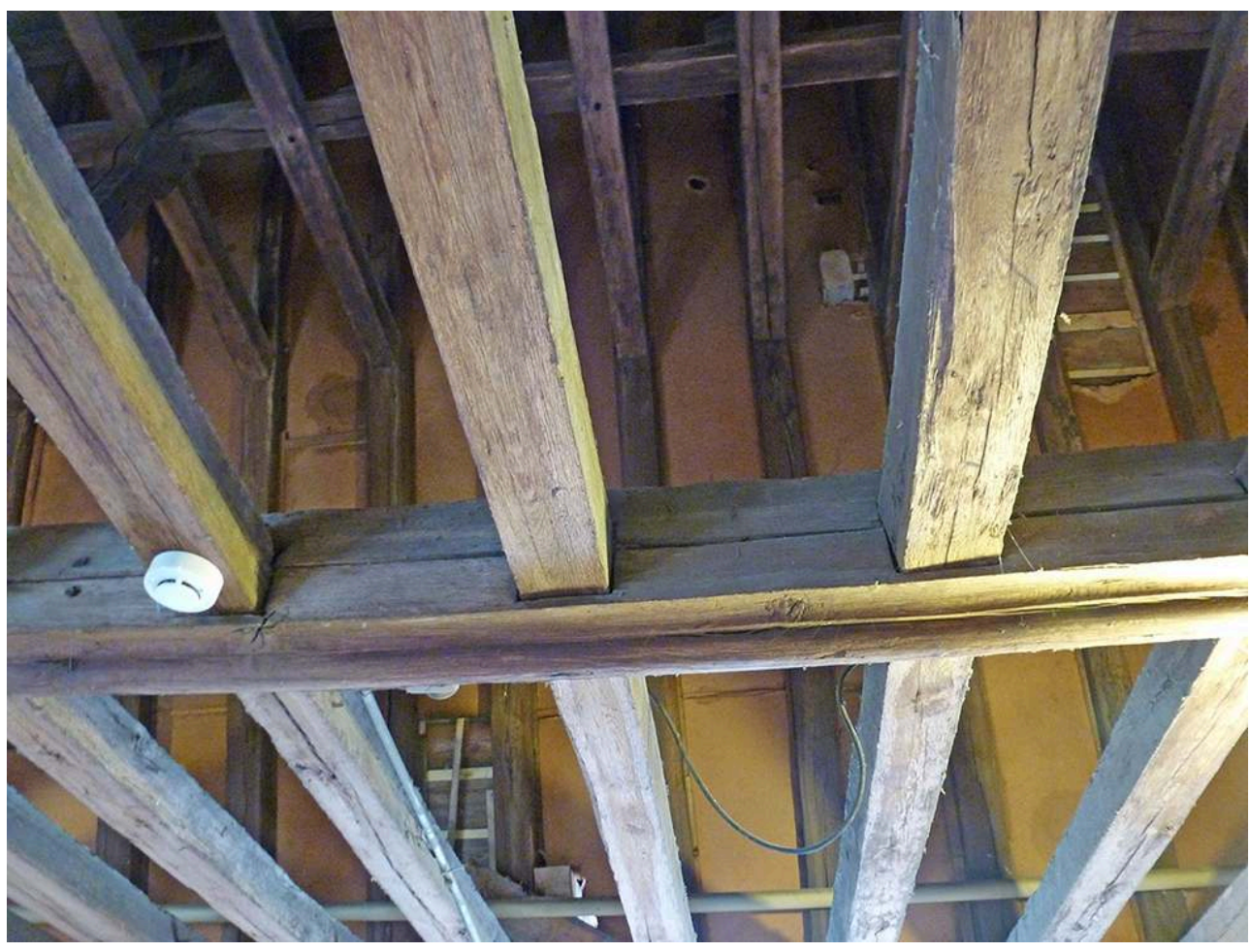

Cl. C. Perrault

62 Celles en position haute maintiennent à distance les poinçons, alors que celles en position basse sont encastrées sous le niveau d'entraits retroussés et développent une mouluration très sobre sur la face inférieure ${ }^{55}$. Elles sont reliées entre elles en plusieurs points par des clefs verticales en bois non traversantes ${ }^{56}$, bloquées par deux chevilles. Ce système de clefs se rapproche de celui répandu dans de nombreux édifices d'Orléans et $d u$ Val de Loire pour solidariser les deux moises des entraits retroussés ${ }^{57}$. Dans les ailes des logis et des grandes salles du château de Langeais, érigées au plus tôt en $1464^{58}$, le liaisonnement des deux liernes par de courts potelets permet de s'opposer au fléchissement de l'élément inférieur placé sous le niveau d'entraits retroussés entre deux murs de refend ou entre un refend et un pignon.

63 Une certaine hétérogénéité se retrouve également dans le traitement des lucarnes de comble (fig. 26). 
Fig. 26 - Gien, lucarne sud obturée, charpente du logis sud (salle Grossouvre)

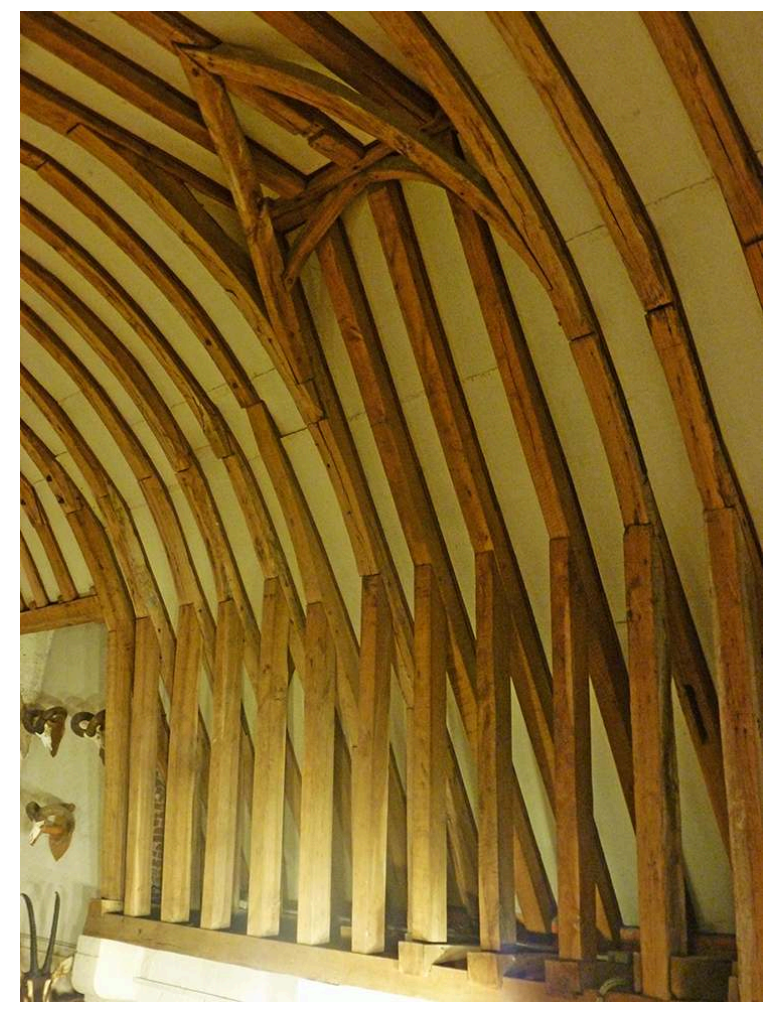

Cl. C. Perrault

64 Deux lucarnes étaient ouvertes sur la ville et deux autres sur la cour pour l'élévation existante du logis sud ${ }^{59}$. On n'en connaît aujourd'hui que l'articulation avec la charpente. Le dispositif de raidissement des entraits retroussés, assemblés aux linçoirs par des liens courbes, paraît s'inspirer de celui utilisé dans l'aile des logis du château de Louis XI, à Langeais, tout en étant mieux intégré à la charpente ${ }^{60}$. Celui-ci ne sera pas reproduit dans les autres corps de bâtiments.

La charpente de la tour ronde sud-est (vers 1491), à trois niveaux d'enrayure, est coiffée d'un campanile (fig. 27). 
Fig. 27 - Gien, enrayure inférieure de la tour ronde sud-est, avec ses entraits moisés

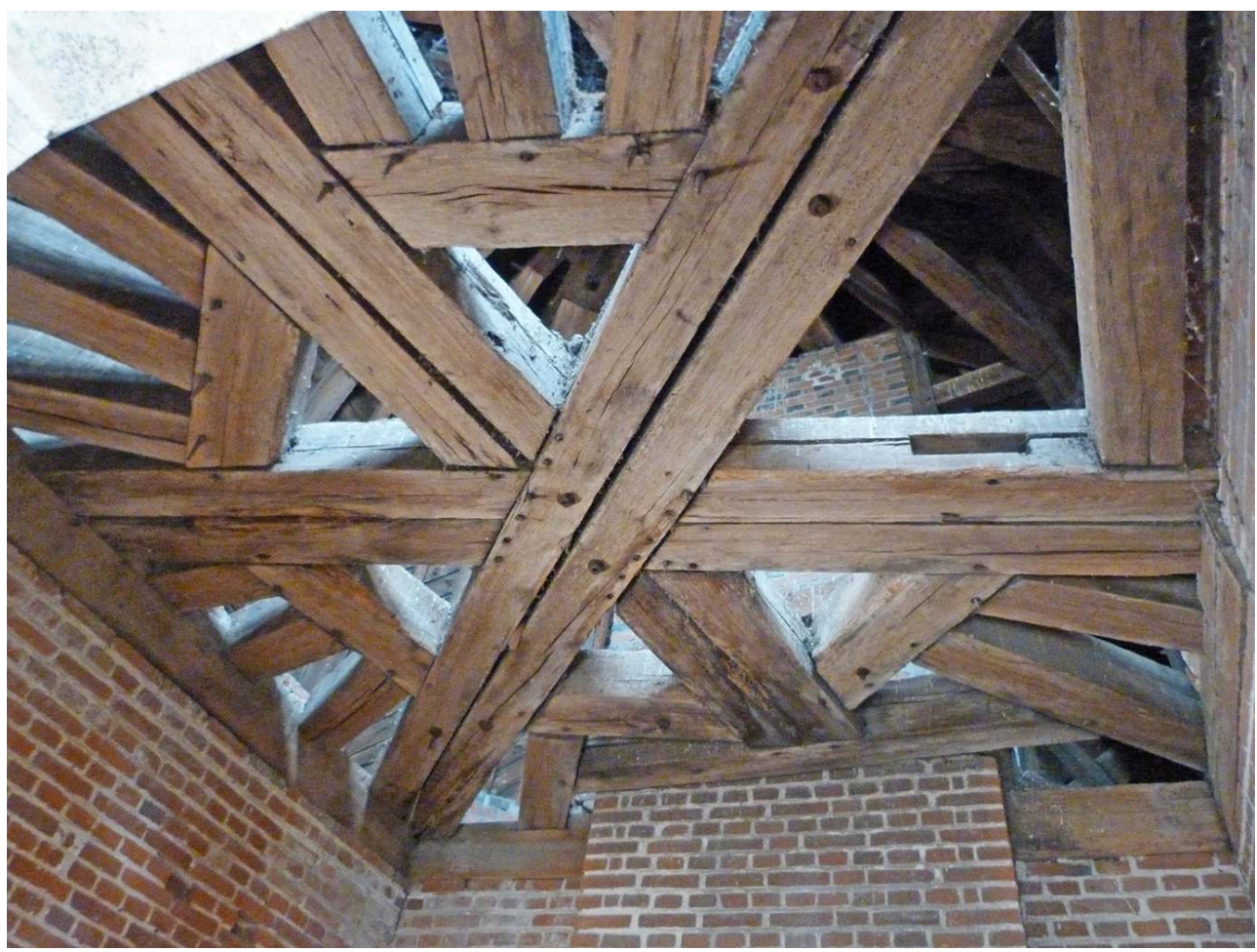

Cl. C. Perrault

66 Le choix original, au premier abord, de reporter les charges verticales sur des entraits moisés semble être une réponse technique à des difficultés d'approvisionnement en bois de forte section ${ }^{61}$, plutôt qu'une tentative d'amélioration de la triangulation des fermes, comme l'ont mise en évidence plusieurs études archéologiques de charpentes à entraits retroussés moisés d'édifices du Val de Loire, notamment de tours ${ }^{62}$. La charpente du donjon de Châteaudun (Eure-et-Loir), érigée vers $1450^{63}$, présente des dispositions comparables, avec deux entraits moisés perpendiculaires au niveau de la première enrayure. La descente de charges est complétée de la troisième à la seconde enrayure par six jambes de force et devait se poursuivre jusqu'à la base de la charpente par d'autres jambes à doubles tenons, assemblées dans les moises ${ }^{64}$.

67 À Gien, le comble de l'aile est (vers 1493) reprend la disposition de salles en enfilade des étages, desservies à l'ouest par une galerie, dont la voûte en berceau brisé est formée par les aisseliers des fermes et des liens légèrement cintrés retombant sur des poteaux d'une cloison (fig. 28). 
Fig. 28 - Gien, combles de l'aile est

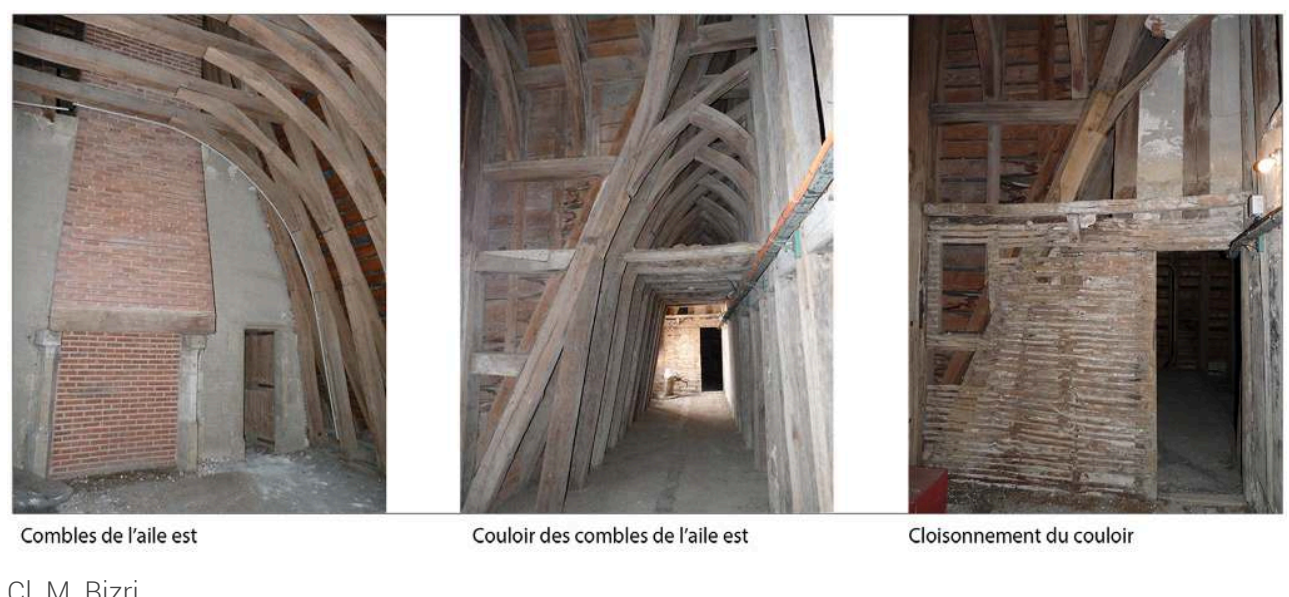

La troisième salle au niveau de la croupe nord est divisée en deux parties par un mur de refend perpendiculaire. Seule la salle centrale est équipée d'une cheminée avec un âtre. La charpente s'apparente à celle de l'aile de Longueville du château de Châteaudun (Eure-et-Loir), érigée vraisemblablement dans les années $1510^{65}$, à la différence près que l'emprise des salles est délimitée par deux cloisons à pan de bois.

D'après la dendrochronologie, les aménagements du comble à Gien interviennent rapidement après le levage de la charpente. Les bois proviennent du même stock que ceux mis en œuvre en charpente ${ }^{66}$. Les rainures des longs blochets facilitent l'insertion en sous-œuvre des poteaux de la cloison, assemblés en tête à tenon-mortaise non chevillé aux aisseliers des fermes ou dans les entraits retroussés, en face des deux grandes lucarnes ouest.

La quantité de bois d'œuvre nécessaire au chantier du château est estimée à plus de trois cent grumes, simplement équarries à la doloire sur les quatre faces pour façonner les chevrons ${ }^{67}$, les pièces les plus longues des charpentes à chevrons formant fermes, en l'absence d'entraits. L'estimation peut être raisonnablement portée à plus de neuf cent grumes de chênes pour l'ensemble du chantier, destinées notamment au solivage et aux fermes de charpente, mais elle reste difficile à préciser. Plusieurs pièces parmi les plus courtes - blochets, jambettes, aisseliers, liens... - peuvent être taillées dans un même arbre, voire dans les branches maitresses. L'absence de perforations obliques sur les pièces de bois de Gien, observées notamment pour l'assemblage de bois en trains flottés sur un cours d'eau, semble privilégier le transport par voie terrestre, alors que le flottage de bois sur la Loire est attesté au Xve siècle pour des édifices d'Orléans ${ }^{68}$. Ainsi, on peut émettre l'hypothèse que la provenance des bois de Gien est locale, tout au plus provient-elle d'un rayon de quelques kilomètres autour de Gien ${ }^{69}$, à l'exception de certaines pièces de bois au gabarit particulier : la poutre maîtresse de la salle ouest du logis sud - salle dite de Linarès -, de 0,62 par 0,65 m de section, est taillée dans un arbre de $0,90 \mathrm{~m}$ de diamètre - soit plus de $2,80 \mathrm{~m}$ de circonférence -, a fait certainement l'objet d'une prospection plus ciblée. Elle comporte d'ailleurs la figuration exceptionnelle d'ours scupltés à ses deux extrémités (fig. 29). 
Fig. 29 - Gien, ours sculpté à l'extrémité nord de la lambourde, plaquée contre la poutre maîtresse du plafond de la salle ouest, dite Linarès, du logis sud

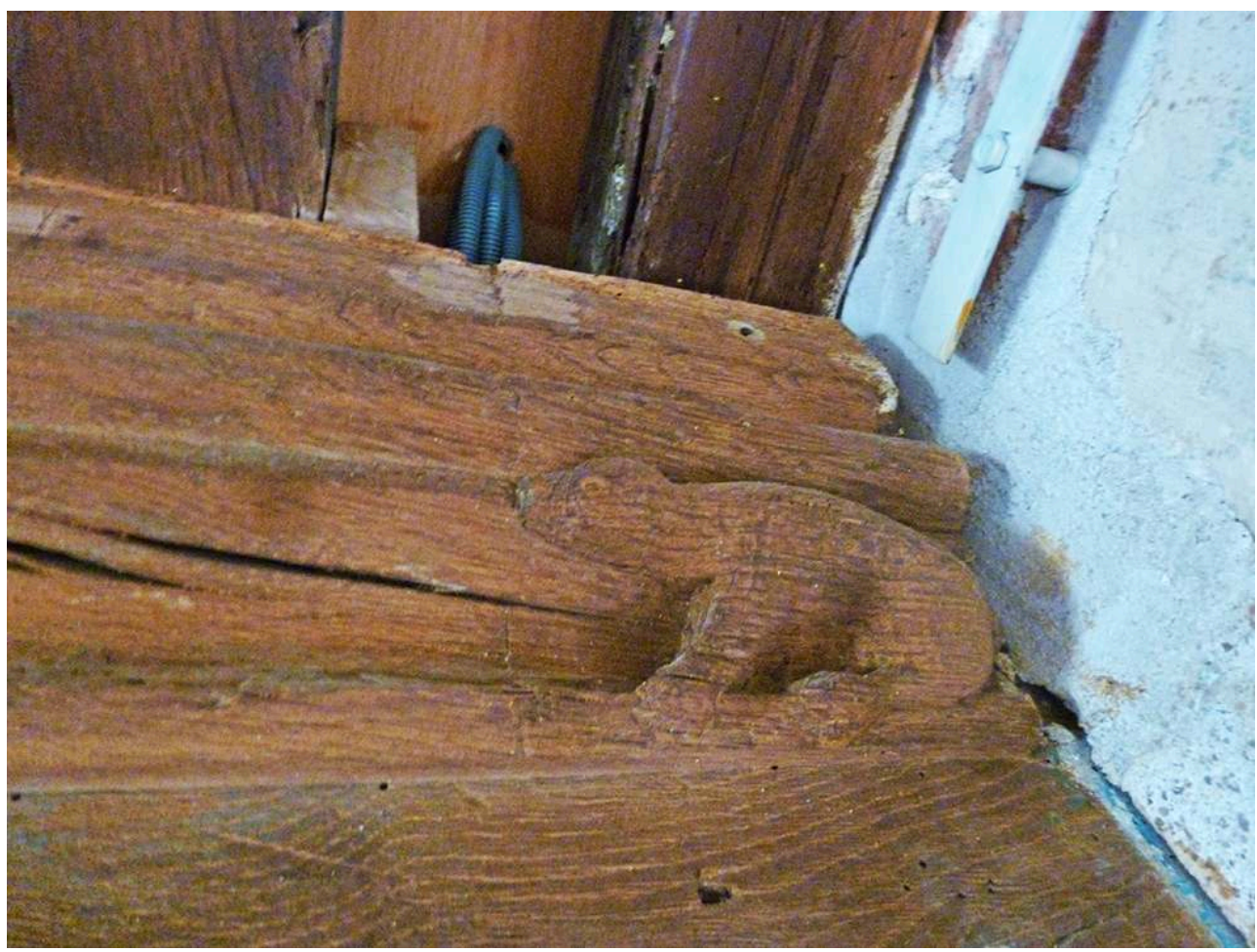

Cl. C. Perrault

\section{Conclusion}

71 Les premières coupes de bois mises en œuvre dans l'édifice apparaissent dès l'automnehiver 1481-1482, soit juste avant qu'Anne de France ne soit dotée du domaine de Gien par son père. Si les bois mis en œuvre au logis sud-ouest (encore en élévation) sont abattus à l'automne-hiver 1481, le projet du chantier est forcément antérieur et il est très probable que l'aile ouest, aujourd'hui disparue, était déjà construite ou rénovée en 1481, selon la logique de progression de chantier identifié d'ouest en est. Par conséquent, si le château de Gien est bel et bien construit par Anne de France, il n'est pas le fruit d'un projet mûri sous la Régence - qui commence seulement vers 1483 -, mais bien un projet envisagé avant qu'Anne de France n'hérite de ce domaine en 1481 . La santé du roi Louis XI se dégrade vers 1482 et il commence à confier les affaires courantes du royaume à Pierre de Bourbon ${ }^{70}$. Les historiens s'accordent à dire que les époux forment alors un duo dans l'exercice du pouvoir ${ }^{71}$ et l'on peut donc légitimement supposer que le projet de la résidence royale de Gien participe autant de la volonté d'Anne de France que de celle de son époux. Le traitement spatial à part égale de la distribution des appartements de l'édifice, pour l'un comme pour l'autre, confirme cette lecture $^{72}$, ainsi que le lieu de Gien, situé non loin des possessions bourbonnaises (Moulins). Il n'a donc pas fallu attendre qu'Anne de France soit dotée de ce domaine pour que le couple de pouvoir, formé par Anne et Pierre, commence les travaux. Le chantier de Gien est donc probablement déjà décidé parmi d'autres chantiers commandés par Louis XI, notamment celui du Plessis-Bourré (1478-1480), où la 
présence des époux Pierre et Anne est aussi mise en avant avec un logis dédié à leur résidence - logis $d u$ «Petit Bourbon $»^{73}$.

La fin du chantier correspond à la fin de la régence exercée par les époux, qui ont commencé d'autres travaux dans leur château bourbonnais à Moulins. Pour Moulins, les travaux engagés par le couple bénéficient d'une documentation comptable: dès 1488, un contrôleur des dépenses est institué par Pierre et on apprend que des transactions pour l'aménagement des jardins sont effectués à partir de 1492 par Anne ${ }^{74}$. Ainsi, ce chantier s'étend entre 1490 et 1497 . Dès lors, le chantier de Gien est progressivement abandonné : l'aile est - comble daté vers 1493 - témoigne de ce délaissement. Le couloir inachevé au nord évoque des hésitations et un repentir dans la distribution de la dernière salle ${ }^{75}$. L'aménagement des combles des tours ouest et centrale n'a pas été prévu, contrairement à celui de la tour orientale, qui est néanmoins resté inachevé. La charpente est adaptée à l'élévation d'une hotte de cheminée ${ }^{76}$, mais les blocs de jambage restent en attente. Comme dans le comble aménagé au-dessus de la chambre haute de la tour est, les jambages de la cheminée ne sont pas sculptés. Les salles ne sont pas plus isolées en torchis au niveau des plafonds. Ces deux éléments constituent autant d'indices du désintérêt porté au chantier de Gien.

Ainsi, le château de Gien aura été principalement marqué par des choix hérités de Louis XI, avec quelques nuances et nouveautés, comme l'expérimentation des chambres hautes en plan individualisé sur une tour d'escalier. L'influence bourbonnaise tient cependant une petite place dans ce programme avec l'adjonction d'un oriel, qui se démarque des châteaux de Louis XI. Situé sur la façade sud (partiellement détruite), il est décoré de mouluration d'une facture gothique. Dans l'aile du château édifié à Moulins - détruit par un incendie en 1755, et dont l'élévation n'est connue que par une gravure du XVII ${ }^{\mathrm{e}}$ siècle d'Israël Sylvestre -, une série de trois oriels scande les logis. À Moulins, cependant, des colonnes classiques soulignent la verticalité des travées des balcons ${ }^{77}$. Après la fin de la Régence, en effet, lorsque les époux font de Moulins leur résidence principale, les choix opérés dans ce lieu diffèrent totalement de ce qui avait été accompli à Gien. Anne de France, assurant à nouveau une courte régence entre 1494 et 1495 , est désormais au contact d'artistes italiens après les campagnes d'Italie. L'architecture entreprise à Moulins traduit dès lors ce tournant avec des réalisations marquant l'entrée dans la Renaissance ${ }^{78}$.

Reçu : 7 novembre 2018 - Accepté : 4 juin 2019

\section{NOTES}

1. La Société d'histoire et d'archéologie du Giennois est de fondation plutôt récente (1923) comparée à la structuration d'autres sociétés savantes des territoires limitrophes : 1847 pour la fondation de la Société des sciences historiques et naturelles de l'Yonne, basée à Auxerre, ou encore 1867 pour la Société d'archéologie et d'histoire du Berry, sociétés toujours actives.

2. G. LOISEAU, "Les seigneurs de Gien de l'origine au $\mathrm{Xv}^{\mathrm{e}}$ siècle ", Bulletin de la Société historique et archéologique du Giennois, 9 (1954), p. 1-13. 
3. G. LOISEAU, «Le Grand-Conseil du Roi Charles VIII, tint ses séances au Château de Gien en 1484 », Bulletin de la Société historique et archéologique du Giennois, 22 (1969), p. 8-45.

4. M. PETIT, Histoire de Gien, 1982 ; M. NOËL, Centre-Val de Loire, Loiret, Gien, Cœur de Ville, rapport de diagnostic archéologique, Inrap Centre-Île-de-France, 2017.

5. S. SALCEDO-MARCHANT, Le château de Gien, mémoire de maîtrise en histoire de l'art, sous la direction de J. Guillaume, université de Tours CESR, 1994, 2 vol.

6. J. Guillaume, "Anne de France à Gien. Le château d'une fille de roi », in Anne de France art et pouvoir en 1500, Paris, 2014, p. 165-176.

7. C. DORMOY, C. ORCEL, L. VAN DER PLAETSEN, Expertise dendrochronologique d'échantillons provenant de l'aile sud du château de Gien (45500), ARC98/R2100D, Saint-Bonnet-de-Chavagne (Archéolabs), Centre d'études supérieures de la Renaissance, université de Tours, 1998.

8. R. MARTIN, Château de Gien, conservation, consolidation et mise en valeur, dossier d'étude préalable, 2008 ; D. LARPIN, Gien château, conservation et valorisation, APS CG 45, 2009.

9. Michel Philippe a mené une vaste enquête sur les sources disponibles pour documenter l'histoire médiévale du château et de la ville de Gien : M. PHILIPPE, « Rapport d'étude documentaire sur le château de Gien, mars 2011 », in M. BIZRI et alii, Gien (Loiret), château-musée international de la chasse (45 $155010 \mathrm{AH}$ ), rapport final de diagnostic archéologique, Orléans, Conseil départemental du Loiret, 2015, t. 1, p. 337-377.

10. M. BIZRI et alii, Gien (Loiret), projet d'aménagement Cour de Ville : place du Château (45.155.014 AH), rapport final d'opération de diagnostic archéologique, Orléans, Conseil général du Loiret, 2012 ; M. BIZRI et alii, Gien (Loiret), château-musée..., ibid.; M. BIZRI et alii, Rapport final d'opération de fouilles préventives du musée de la Chasse-château de Gien : rez-de-chaussée bas, terrasse sud, belvédère Ouest, Orléans, Service archéologie préventive du département du Loiret, à paraître.

11. C. PERRAULT, Datation par dendrochronologie : coffrage de la cave du château de Gien (45), Besançon (Cèdre) et Orléans (Conseil général du Loiret), 2011 ; C. PERRAULT, Datation par dendrochronologie, château de Gien (Loiret), Besançon (Cèdre) et Orléans (DRAC/MH Centre), 2014.

12. M. PHILIPPE, « Rapport d'étude... », op. cit., l'auteur cite : PARIS, Archives nationales, K 1206, pièce $\mathrm{n}^{\circ} 33$, octobre 1199.

13. M. PHILIPPE, « Rapport d'étude... », ibid., l'auteur cite : PARIS, Archives nationales, P 1370-1, cote 1858, décembre 1481.

14. J. MESQUI et C. RIBÉRA-PERVILLÉ, "Les châteaux de Louis d'Orléans et leurs architectes (1391-1407)", Bulletin monumental, 138/3 (1990), p. 293-345; F. TOURNADRE, "Châteauneuf-surLoire. Découvertes inédites sur la grande salle du château », Bulletin monumental, 168/4 (2010), p. 374-378.

15. Présence des ducs de Bourbon, de Bretagne, d'Alençon, des comtes de Clermont et d'Armagnac.

16. L. MARTIN, "Un grand mariage princier au Château de Gien en 1410 », Bulletin de la Société historique et archéologique du Giennois, 9 (1954), p. 14-16.

17. Louis II d'Orléans, marié à sa sœur Jeanne, futur Louis XII, sort de la disgrâce sous le règne de Charles VIII, avant d'accéder au trône à la mort de ce dernier en 1498.

18. J.-F. LASSAlmonie, "Anne de France, dame de Beaujeu. Un modèle féminin d'exercice du pouvoir dans la France de la fin du Moyen Âge ", in É. BOUSSMAR, J. DUMONT, A. MARCHANDISSE et B. SCHNERB (dir.), Femmes de pouvoir, femmes politiques durant les derniers siècles du Moyen Âge et au cours de la première Renaissance, Bruxelles, 2012, p. 129-146.

19. Charles VIII (dauphin, héritier du trône) est encore mineur au décès du roi en 1483. Sa sœur, Anne, veille notamment à son éducation. Charles dauphin est progressivement associé au pouvoir à partir de 1488, puis Charles VIII accède au trône en 1491 à l'âge de vingt et un ans, cf. J.F. LASSALMONIE, « Anne de France... », ibid. 
20. Y. BRUAND, "Le château de Billy », in Congrès archéologique de France, $146^{e}$ session, Bourbonnais, Paris, 1988, p. 75-81 ; Y. BRUAND, «Le château de Bourbon-l'Archambault », in Congrès archéologique de France..., ibid., p. 97-109 ; y. BRUAND, « Le château ducal de Moulins », in Le duché de Bourbon : des origines au Connétable, Saint-Pourçain-sur-Sioule, 2001, p. 55-64.

21. Trente-six échantillons sur les cinquante-quatre collectés présentent un aubier complet jusqu'à l'écorce. Dans un souci de préservation purement esthétique des plafonds des salles d'exposition du musée et contraint par l'équarrissage quasi-parfait des solivages, les niveaux inférieurs ont fait l'objet de rares prélèvements d'échantillons, au profit des charpentes de comble non exposées à la vue des visiteurs.

22. Ces propositions de datation ne sont qu'indicatives et supposent que la mise en œuvre des bois soit effective rapidement, juste après le dernier abattage observé pour chaque ensemble.

23. Par exemple, pour la galerie est, une solive est façonnée dans un chêne coupé en automnehiver 1489-1490, alors que les bois de la charpente correspondante le sont au printemps 1486, en automne-hiver 1488-1489 et en automne-hiver 1489-1490. De même, dans le logis occidental, une planche de coffrage de voûte du rez-de-chaussée bas est datée peu après 1482 sur aubier incomplet. Une solive de plafond de la salle contiguë provient même d'un arbre exploité en automne-hiver 1483-1484, alors qu'en charpente, les bois mis en œuvre sont abattus les deux années précédentes.

24. Jean Guillaume proposait la présence d'une pièce disparue, ayant rôle de salle, et un étage où une galerie de bois pouvait communiquer avec l'église, cf. J.GUILLAUME, « Anne de France... », op. cit., p. 168.

25. M. BIZRI et alii, Rapport final d'opération de fouilles préventives..., op. cit.

26. M. BIZRI et alii, Rapport final d'opération de fouilles préventives..., ibid. Jean Guillaume supposait, quant à lui, que ces bâtiments avaient été détruits une fois la construction du château achevé (J. Guillaume, « Anne de France... », op. cit., p. 172-173).

27. Archives dép. du Loiret, série $C$, suppl. 5 , route d'Orléans à Briare.

28. Les investigations archéologiques ont mis en évidence une maçonnerie arasée d'environ $1,10 \mathrm{~m}$ de large sur l'esplanade au nord-ouest. Elle peut se rapporter à une petite section de cette enceinte, cf. M. BIZRI et alii, Gien (Loiret), projet d'aménagement..., op. cit., p. 56.

29. Maison médiévale encore peu étudiée, datations des charpentes par dendrochronologie: 1282 et 1359 : C. PERRAULT et O. GIRARDCLOS, Datation par dendrochronologie des charpentes de la maison du chanoine, à Gien (45), Besançon (Cèdre), 2006. Les diagnostics archéologiques menés sur la place au-devant de l'église et sur la cour nord de l'église ont révélé quelques traces ténues d'habitats médiévaux en cour nord et un mur sur l'esplanade. Ils ne permettent pas de conclure ni sur la densité d'un habitat qui a pu s'étendre sur ce promontoire, ni sur ses fonctions, cf. M. BIZRI et alii, Gien (Loiret), projet d'aménagement..., ibid. et M. BIZRI et alii, Gien (Loiret), château-musée..., op. cit.

30. Notamment en raison du bâtiment qui s'appuie contre cette dernière dont les premiers niveaux d'occupation ont été datés du $\mathrm{X}^{\mathrm{e}}$ siècle par ${ }^{14} \mathrm{C}$. M. BIZRI et alii, Rapport final d'opération de fouilles préventives..., op. cit.

31. C. PERRAULT, Datation par dendrochronologie: coffrage de la cave..., op.cit. Les datations ont été effectuées sur des douelles en réemploi laissées dans les coffrages des voûtes d'ogive et dont l'aubier n'est pas conservé. Toutefois, l'arbre est coupé après 1470. Il est donc proposé un abattage de l'arbre entre 1483 et 1507, en fonction de la croissance restituée.

32. M. BIZRI et alii, Rapport final d'opération de fouilles préventives..., op. cit.

33. La tour est parfois dénommée par les habitants de Gien, tour Charlemagne. En 1428-1429, la ville de Gien est occupée par les Anglais, défaits en 1429 à Orléans. Le nom de la tour semble se rapporter à la mémoire de ces événements, cf. G. LOISEAU, Les seigneurs..., op. cit. 
34. Avant la restauration intervenue en 2014, les niveaux supérieurs avaient déjà perdu leur enduit, alors que les niveaux inférieurs conservaient un enduit moderne de restauration de couleur rosâtre.

35. Ces dispositions rappellent celles de la tour D de Châtillon-sur-Indre : P. LANGEUIN, « Les tours de flanquements quadrangulaires du château de Châtillon-sur-Indre : archaïsme ou précocité ?", Bulletin monumental, 168/1 (2010), p. 33-37.

36. M. BIZRI et alii, Gien (Loiret), château-musée..., op. cit., chapitre 4.

37. Pièce de bois en réemploi provenant d'anciennes constructions du château.

38. Au Plessis-lès-Tours, des galeries de bois relient entre eux différents corps de bâtiments édifiés sous Louis XI et, notamment, le logis à la chapelle: A. SALAMAGNE, "Le Plessis et les résidences royales en Touraine à l'avènement de Louis XI », Bulletin de la Société archéologique de Touraine, 60 (2014), p. 173-184. C'est sans doute par comparaison avec ce site que Jean Guillaume propose un tel dispositif reliant le château de Gien à l'église, cf. J. GuillaumE, « Anne de France... », op. cit. Toutefois, aucun indice ne permet d'étayer cette hypothèse.

39. Ces travaux sont rapportés par l'abbé Vallet (1788-1828) sur la base d'une documentation plus ancienne, mais moderne (l'abbé Lebeuf, 1687-1760) : l'abbé Vallet rapporte, notamment, la construction du château en 1490, la reconstruction de l'église entre 1494 et 1499 ainsi que les réparations du pont et du château à cette date. Un jubilé est accordé par le pape vers 1486/1489 pour permettre aux fidèles de contribuer aux réparations de l'église, alors presque en état de ruine. Archives dép. du Loiret, 1 Mi 159, abbé Vallet, Histoire de la ville de Gien sur Loire, 1818. On peut effectivement, à partir de ces mentions, attribuer la reconstruction de l'église de Gien à Anne de France, édification contemporaine d'autres chapelles dans le domaine bourbonnais : au château de Moulins (chapelle «neuve » en cours de couvrement en 1497-1503) ou au château de Bourbon-l'Archambault (achevée au XVI ${ }^{\mathrm{e}}$ siècle), cf. Y. BRUAND, « Le château ducal... », op. cit.

40. C. ALIX, «Les maisons en pans de bois d'Orléans du début du XIV au début du XVII siècle : bilan de treize années de recherche ", in C. ALIX et F. ÉPAUD (dir.), La construction en pan de bois au Moyen Âge et à la Renaissance, Rennes/Tours, 2013, p. 221-270.

41. É. MILLET, «Les tuileries d'Isdes (Loiret) du XVIII ${ }^{\mathrm{e}}$ au $\mathrm{Xx}^{\mathrm{e}}$ siècle ", in Les briquèteries-tuileries de Sologne, Cher, Loir-et-Cher, Loiret, s. 1., 2012 [Groupe de recherches archéologiques et historiques de Sologne, « hors-série »], p. 77-98.

42. S. BRYANT, Construire au Moyen Âge en région Centre: économie de la pierre et techniques de construction en région Centre $d u \mathrm{XII}^{e}$ au $\mathrm{XVI}^{e}$ siècle. L'apport des chantiers d'archéologie préventive, thèse de doctorat, université Paris 1 Panthéon-Sorbonne, 2014, p. 361.

43. Cf. B. TOULIER, Châteaux en Sologne, Paris, 1991, p. 287-303 et Les briquèteries-tuileries de Sologne..., op. cit.

44. Les argiles utilisées pour la faïencerie de Gien (créée en 1821) sont issues du tri de la kaolinite et des lentilles argileuses des argiles à silex sénoniennes, cf. M. GIGOUT et N. DESPREZ, Carte géologique de la France, Gien (XXIV-21), Orléans, 1969, p. 21.

45. François Énaud avait déjà effectué le lien entre la polychromie de Gien et le château du Plessis-lès-Tours et l'influence qu'a eu cette mode constructive en Val de Loire dans les constructions des personnages de l'entourage de Louis XI et Charles VIII : F. ÉNAUD, « Le château de Gien (Loiret), bel exemple d'architecture de briques », IBI Bulletin, 46 (1988), p. 9-20. Voire aussi la synthèse récente d'Alain Salamagne : A. SALAMAGNE, «Louis XI et l'architecture brique et pierre en Val de Loire », in M. BOUDON-MACHUEL et P. CHARRON (dir.), Art et société à Tours au début de la Renaissance, Turnhout, 2016, p. 41-58.

46. L. GAUGAIN, Amboise : un château dans la ville, Rennes, 2014, p. 69-93.

47. A. SALAMAGNE, "Le Plessis et les résidences royales... », op. cit. et A. SALAMAGNE, "Louis XI et l'architecture brique... », op. cit. 
48. C. ALIX et J. NOBLET, « Les charpentes à entrait retroussé moisé : exemples orléanais des $\mathrm{XV}^{\mathrm{e}}$ et $\mathrm{XVI}^{\mathrm{e}}$ siècles ", Revue archéologique du Centre de la France, 48 [2009], en ligne [http://racf.revues.org/ 1337], consulté le 29 octobre 2018.

49. V.VISCUSI, Analyse archéologique du bâti préalable à la restauration d'une partie du château: Auxonne, château Louis XI, place du Château : rapport de fouilles, Dijon, Inrap Bourgogne-FrancheComté, 2017.

50. J.-F. LASSALMONIE, " Anne de France... », op. cit.

51. B. TOULIER, Châteaux... ", op. cit., p. 78.

52. S. SALCEDO-MARCHANT, La chambre-haute : étude typologique, mémoire de DEA en histoire de l'Art, sous la direction de J. Guillaume, université de Tours CESR, 1998.

53. G. FRAISSE, «Enquête sur la diffusion d'une forme architecturale : l'escalier à vis octogonal sous encorbellement de plan carré ", in Chastels et maisons fortes 6. Chagny. Centre de castellologie de Bourgogne, 6 (2005), p 269-285.

54. F. TOURNADRE, «Beaulieu-lès-Loches. Trois charpentes du XIV siècle. Nouveaux apports sur l'habitat médiéval de la ville », Bulletin monumental, 170/2 (2012), p. 153-159.

55. Elle est également présente sur les sous-faîtières des charpentes du logis sud et du logis de l'Oriel.

56. Ces clefs sont appelées, selon les régions, « pigeons » ou « prisonniers ».

57. C. ALIX et J. NOBLET, « Les charpentes à entrait... », op. cit.

58. Datation par dendrochronologie et étude archéologique réalisées, respectivement, par Christophe Perrault (Cèdre) et Lucie Gaugain et financées par la société Kléber Rossillon, à qui l'Institut de France, propriétaire du château, en a confié l'animation.

59. Les deux lucarnes côté ville ont été restituées dans le chantier de 2014 par le cabinet Larpin. 60. À Langeais, les liens courbes reposent directement sur le cours de sous-faîtières ou sur un élément intercalé entre deux fermes contiguës et reçoivent les pieds des aisseliers tronqués. À Gien, les paires de liens courbes jouent le rôle des aisseliers et sont fixées en tête dans des embrèvements d'un même entrait retroussé.

61. Ces entraits sont constitués de deux brins de chêne faiblement équarris et disposés dans le même plan horizontal, qui enserrent les pieds de jambettes et de chevrons.

62. C. ALIX et J. NOBLET, « Les charpentes à entrait... », op. cit.

63. Un marché de Dunois avec un charpentier est conclu le 4 décembre 1450. Les historiens s'accordent à accepter cette date pour la charpente : DR. LESUEUR, « Château (de Châteaudun) », in Congrès archéologique de France, 93e session, Orléans, 1930, Paris, 1931, p. 476-520 ; M. CHATENET, Le château de Châteaudun, 1999.

64. Cette hypothèse est déduite de l'observation des mortaises orphelines sur la face supérieure des entraits moisés de la première enrayure. Ce cas de figure a été observé pour les entraits retroussés moisés de la deuxième et de la troisième enrayure de la charpente du clocher de l'église Saint-Martin d'Ouzouer-sur-Trézée (Loiret), vers 1498. Les datations ont été réalisées en 2014 par le laboratoire Cèdre. Dans la tour de Gien, l'assemblage des têtes des jambes est moins lisible, mais pourrait se faire dans la même mortaise que celle occupée par les pieds des jambes du niveau supérieur, sans chevillage.

65. Selon Monique Chatenet, la construction de l'aile nord, qui a débuté sous François I ${ }^{\mathrm{er}}$ d'Orléans-Longueville, reprend, après de nombreux deuils, à partir de 1509-1510. Les travaux s'achèvent par la construction du grand escalier vers 1518 : M. CHATENET, Le château..., op. cit.

66. C'est le cas pour la cloison séparant les salles du couloir. Le sommier ouest portant la hotte de la cheminée de la salle centrale a fait l'objet d'une datation moins précise, en raison du très mauvais état de conservation de l'aubier, ce qui n'est pas le cas du cœur de la pièce de bois. Mais il fait probablement partie du même stock de bois que celui utilisé en charpente et pour la cloison.

Bulletin du centre d'études médiévales d'Auxerre | BUCEMA, 23.1 | 2019 
67. Un chevron est égal à un arbre.

68. C. ALIX, « Les maisons en pans de bois d'Orléans... », op. cit.

69. Les séries de croissance des arbres présentent les plus fortes similitudes avec les références de la base de données Cèdre les plus proches de Gien : les charpentes de l'église d'Ouzouer-surTrézée et de l'ancien presbytère de Saint-Gondon suggèrent, en effet, une provenance des bois de la même aire géographique. Les résultats de cette approche expérimentale sont toutefois à nuancer en raison des qualités statistiques hétérogènes de l'ensemble des références testées. De plus, certaines zones ne sont pas représentées pour la période considérée.

70. J.-F. LASSALMONIE, « Anne de France... », op. cit.

71. J.-F. LASSALMONIE, « Anne de France... », ibid.

72. J. GUILLAUME, « Anne de France... », op. cit.

73. A. SAlAMAGNE, op. cit.

74. Y. BRUAND, « Le château ducal... », op. cit.

75. Les mortaises sont préparées dans les aisseliers les plus au nord pour recevoir les éléments de la cloison du couloir.

76. Les empanons et l'arêtier de la croupe est, situés dans l'environnement proche de la hotte de cheminée, ne sont pas raidis par une jambette et un aisselier. L'absence de mortaise orpheline suggère qu'ils ne l'ont jamais été et écarte l'hypothèse d'un aménagement postérieur se caractérisant par un démontage des pièces encombrantes.

77. Y. BRUAND, « Le château ducal... », op. cit.

78. y. BRUAND, "Le château ducal... ", ibid. ; J. GUILLAUME, " Le portique Renaissance du château de Moulins ", in Le duché de Bourbon: des origines au Connétable, Saint-Pourçain-sur-Sioule, 2001, p. 65-70.

\section{RÉSUMÉS}

Le château de Gien, construit en marge du diocèse d'Auxerre, a fait l'objet d'une réévaluation récente de la chronologie de sa construction et de son implantation. Les auteurs de l'article s'attachent à mettre en évidence le caractère singulier de cet édifice de la fin $\mathrm{du} \mathrm{Xv}^{\mathrm{e}}$ siècle, dont les choix constructifs, étudiés d'un point de vue archéologique et dendrochronologique, sont remis en perspective dans les productions de la même période. Ainsi, l'usage des matériaux - la brique en premier lieu -, leur mise en œuvre avec quelques expérimentations - la chambre haute notamment - et le chantier d'installation des logis gommant les vestiges antérieurs du site castral, traduisent les intentions des commanditaires. Anne de France, fille de Louis XI, régente du royaume sous la minorité de Charles VIII, et Pierre de Bourbon poursuivent à travers cet édifice, installé à la jonction des duchés orléanais, bourguignons et bourbonnais, l'œuvre architecturale et politique de Louis XI, entre rupture et continuité.

The castle of Gien built on the sidelines of the diocese of Auxerre has been the subject of a recent reassessment of the chronology of its construction and implantation. The authors of the article highlight the singular character of this building of the late fifteenth century whose constructive choices, studied from an archaeological and dendrochronological point of view are put in perspective in the productions of the same period. Thus, the use of materials - the brick in the first place -, their implementation with some experiments - upper chamber especially - and the 
construction site erasing the previous vestiges of the castral site, reflect the intentions of the sponsors. Anne de France, daughter of Louis XI, regent of the kingdom under the minority of Charles VIII, and Pierre de Bourbon pursue through this building installed at the junction of the duchies of Orleans, Burgundy and Bourbonnais the architectural and political work of Louis XI between rupture and continuity.

INDEX

Mots-clés : château, Gien, Anne de France, brique, dendrochronologie

Keywords : Castle, Gien, Anne de France, brick, dendrochronology

\section{AUTEURS}

MÉLINDA BIZRI

Archéologue, UMR 6298 ARTEHIS, Université de Bourgogne

SYLVIE MARCHANT

Historienne de l'art, DRAC région Centre-Val de Loire

CHRISTOPHE PERRAULT

Dendrochronologue, Cedre, Besançon 